\title{
Le syndicalisme britannique dans la première mondialisation (1868-1914)
}

British trade-unions and globalisation: the 1868-1914 experience

\section{Yann Béliard}

\section{(2) OpenEdition}

\section{Journals}

Édition électronique

URL : http://journals.openedition.org/rfcb/1134

DOI : $10.4000 /$ rfcb. 1134

ISSN : 2429-4373

Éditeur

CRECIB - Centre de recherche et d'études en civilisation britannique

\section{Édition imprimée}

Date de publication : 27 juillet 2009

Pagination : 15-43

ISBN : 978-2-9115-8028-4

ISSN : 0248-9015

Référence électronique

Yann Béliard, «Le syndicalisme britannique dans la première mondialisation (1868-1914) », Revue Française de Civilisation Britannique [En ligne], XV-2 | 2009, mis en ligne le 01 novembre 2016, consulté le 19 avril 2019. URL : http://journals.openedition.org/rfcb/1134 ; DOI : 10.4000/rfcb.1134

\section{(c) (†) $\odot$}

Revue française de civilisation britannique est mis à disposition selon les termes de la licence Creative Commons Attribution - Pas d'Utilisation Commerciale - Pas de Modification 4.0 International. 


\title{
Le syndicalisme britannique dans la première mondialisation $(\mathbf{1 8 6 8 - 1 9 1 4})$
}

\author{
Yann BÉLIARD \\ Université Paris 3 - Sorbonne Nouvelle
}

\begin{abstract}
Que ce soit en Grande-Bretagne ou ailleurs, la mondialisation est souvent présentée comme un phénomène radicalement nouveau et fondamentalement néfaste pour les salariés, face auquel le syndicalisme serait par définition impuissant. Pourtant, le caractère international du capitalisme ne date pas d'hier. International, le capitalisme marchand de la fin du Moyen-Âge l'était déjà et ce fut au cours de la seconde moitié du long XIXe siècle, entre approximativement 1870 et 1914, que le capitalisme industriel acquit la dimension planétaire que nous lui connaissons aujourd'hui. C'est bien cette période, et non la nôtre, qui mérite d'être considérée comme sans précédent du point de vue de la «multi-, pluri-, trans-, extranationalisation » des échanges commerciaux et des mouvements de capitaux ${ }^{2}$. Or à cette période, que Hobsbawm a qualifiée d' " ère des empires » (the age of empire) ${ }^{3}$ et que d'autres, plus récemment, ont rebaptisée « première mondialisation » (the first globalisation), tous les syndicalistes ne voyaient pas dans l'internationalisation du capitalisme une calamité. Comme l'a mis en évidence la politiste américaine Suzanne Berger, les syndicalistes français de la Belle Epoque avaient même plutôt tendance à voir dans la mondialisation qui se déroulait sous leurs yeux un vecteur pour leur combat, voire la condition sine qua non de l'avènement d'une république sociale sans frontières ${ }^{4}$. Qu'en était-il de l'autre côté de la Manche? Telle est la question à laquelle voudrait tenter de répondre cet article.
\end{abstract}

«Trade-unionisme» et «mondialisation» sont deux termes dont le rapprochement, il n'y a pas si longtemps, aurait pu prêter à sourire. Aux yeux des militants français ou allemands, leurs homologues britanniques sont en effet longtemps passés pour d'irréductibles insulaires, fort peu préoccupés des réalités

\footnotetext{
${ }^{1}$ Fernand BRAUDEL, La dynamique du capitalisme, Paris : Flammarion, 1985, 123 p. Michel BEAUD, Histoire du capitalisme de 1500 à nos jours, Paris : Seuil, 1987, 374 p.

${ }^{2}$ Annie FOUQUET, Udo REHFELDT et Serge LE ROUX (dir.), Le Syndicalisme dans la mondialisation, Paris : Les Editions de l'Atelier / Les Editions Ouvrières, 2000, p. 213.

${ }^{3}$ Eric J. HOBSBAWM, The Age of Empire 1875-1914, Londres : Weidenfeld \& Nicolson, 1987, 404 p.

${ }^{4}$ Suzanne BERGER, The First Globalization. Lessons from the French (2002), publié en français sous le titre Notre première mondialisation. Leçons d'un échec oublié, Paris: Editions du Seuil et La République des idées, 2003, 95 p. Sur le cas français, voir aussi Susan MILNER, The Dilemmas of French Internationalism. French Syndicalism and the International Labour Movement 1900-1914, Oxford : Berg, 1990, 260 p.
} 
internationales ${ }^{5}$. L'historiographie du mouvement ouvrier outre-Manche semble de prime abord leur donner raison, si on en juge par la faible place attribuée à la dimension internationale dans les histoires «classiques» du trade-unionisme produites successivement par Sidney et Beatrice Webb, G.D.H. Cole et Raymond Postgate, Andrew Morton et George Tate ou encore Henry Pelling ${ }^{6}$. Quant aux histoires «canoniques » du mouvement ouvrier international publiées côté français, elles reconnaissent au trade-unionisme un rôle pionnier mais lui réservent toujours un espace à part, à l'écart du courant général ${ }^{7}$. Pourtant, depuis quelques années, ce cliché est mis à mal. La mondialisation en cours, modifiant le regard que nous portons sur le passé, pousse de plus en plus d'historiens à explorer une dimension transnationale jusqu'alors négligée, et notamment ceux qui s'intéressent à l'histoire sociale $^{8}$. Il est une coïncidence si évidente qu'elle a peut-être été oubliée : celle de la croissance du Trades Union Congress (TUC) - il est fondé en 1868 - et de l'internationalisation du capitalisme - elle prend son envol dans les années 1870 et ne sera stoppée que par le déclenchement de la Première Guerre mondiale. Or le renouvellement en cours de l'histoire ouvrière invite à redécouvrir la jeunesse du syndicalisme britannique. Et si les trade-unions n'avaient pas vécu en vase clos? Et si leurs bâtisseurs non seulement avaient été contraints de prendre position face à la globalisation, mais en avaient été, bon gré, mal gré, pour le meilleur et pour le pire, des acteurs de premier plan? Leurs expériences les placèrent devant bien des dilemmes : collaborer un peu, beaucoup ou pas du tout avec les « prolétaires de tous les pays »; accompagner, tenter de brider ou de renverser la mondialisation capitaliste ; soutenir, essayer de réformer ou de combattre l'entreprise impériale. L'examen des réponses pratiques voire théoriques qu'ils apportèrent à ces défis présente un double intérêt : celui de replacer l'aventure du trade-unionisme dans un contexte global d'une part ; celui de mettre en perspective le discours actuel sur les rapports entre syndicalisme et mondialisation d'autre part.

\section{Le Trades Union Congress (TUC) et le mouvement ouvrier international : un engagement sous réserve}

«La nécessité de dépasser le cadre national et de constituer des ensembles solidaires plurinationaux ou transnationaux (...) est présente dès les débuts de

\footnotetext{
${ }^{5}$ Wolfgang ABENDROTH, A Short History of the European Working Class, New York : Monthly Review Press, 1972, 204 p. Voir aussi Andrew J. TAYLOR, Trade Unions and Politics. A Comparative Introduction, Londres : Palgrave Macmillan, 1989, 227 p.

${ }^{6}$ Sidney et Beatrice WEBB, The History of Trade Unionism ( $1^{\text {ère }}$ édition : 1894), Londres : Longmans Green, 1950, 784 p. G.D.H. COLE et Raymond POSTGATE, The Common People 1746-1946, Londres : Methuen, 1946, 742 p. Andrew L. MORTON et George TATE, The British Labour Movement 1770-1920, Londres : Lawrence and Wishart, 1956, 313 p. Henry PELLING, A History of British Trade Unionism ( $1^{\text {ère }}$ édition : 1963), Harmondsworth : Penguin, 1969, 286 p.

${ }^{7}$ Edouard DOLLEANS, Histoire du mouvement ouvrier ( $1^{\text {ère }}$ édition : 1939), Paris : Armand Colin, 1967, 1185 p., 3 volumes. Georges LEFRANC, Le syndicalisme dans le monde, Paris : PUF, 1975, 128 p. René MOURIAUX, Le syndicalisme dans le monde, Paris : PUF, 1993, 128 p. ${ }^{8} \mathrm{Du}$ colloque 'New Directions in Comparative and International Labour History' (organisé par l'International Centre for Labour Studies à l'Université de Manchester en mars 1999) jusqu'au colloque 'A World of Labour, Transnational and Comparative Approaches' (organisé par la Society for the Study of Labour History à l'Université d'Ulster en septembre 2008), cet angle d'attaque a suscité au cours des dix dernières années un intérêt grandissant.
} 
l'action syndicale organisée, au milieu du XIXe siècle ${ }^{9}$. La question, toutefois, ne peut que prendre une coloration particulière dans un pays qui fut longtemps la seule grande nation industrielle, qui fit office d' «atelier du monde » jusqu'à la fin des années 1860 et dont le leadership mondial se maintint, malgré l'émergence de puissances industrielles rivales, jusqu'en 1914. On a souvent expliqué l'apparente indifférence des trade-unionistes à l'égard des affaires étrangères par le bénéfice que tirait l'ensemble de la classe ouvrière britannique (ou sa seule fraction « aristocratique ») de la position dominante de la bourgeoisie nationale dans l'ordre économique mondial : pourquoi les trade-unionistes auraient-ils travaillé à unir le prolétariat international, pourquoi auraient-ils œuvré au renversement du système capitaliste à l'échelle de la planète (ce que prétendaient faire et les syndicats sociaux-démocrates allemands, et la CGT syndicaliste révolutionnaire française), quand les miettes tombées de la table où festoyaient les classes dominantes assuraient à l'ouvrier britannique un niveau de vie que n'importe quel ouvrier du monde aurait jugé enviable ? En Grande-Bretagne, le syndicalisme aurait donc pris un visage inséparablement insulaire et réformiste du fait de la complicité objective des salariés et / ou de leurs représentants avec le patronat dans l'exploitation du plus vaste empire colonial que le monde ait jamais connu ${ }^{10}$. L'interprétation marxiste, sommairement résumée ci-dessus, contient plus d'une once de vérité, ainsi qu'il sera montré plus loin. Mais les syndicalistes continentaux, forçant le trait, ont parfois eu tendance à évoquer un isolationnisme britannique originaire proprement anhistorique. Or, du fait de l'internationalisation croissante des économies, les syndicalistes britanniques furent bel et bien contraints, décennie après décennie, de tisser des liens avec les travailleurs étrangers.

\section{L’internationalisme sans le socialisme ni la révolution}

Le TUC n'en fait guère état dans ses histoires officielles et les histoires du socialisme européen ne le mentionnent pas toujours, mais la fondation du TUC, en 1868, doit beaucoup à celle de l'Association Internationale des Travailleurs (AIT) quatre ans auparavant ${ }^{11}$. En effet, les militants britanniques qui participèrent aux premiers pas de l'AIT en 1864 furent à peu de choses près les mêmes qui prirent

\footnotetext{
${ }^{9}$ Annie FOUQUET, Udo REHFELDT et Serge LE ROUX (dir.), Le Syndicalisme dans la mondialisation, op. cit., p. 21.

${ }^{10}$ Dans un article écrit en 1949 puis révisé en 1963, E.J. Hobsbawm résumait ainsi ce point de vue : «Le réformisme britannique trouve sans aucun doute ses origines dans un siècle entier de domination sans partage du Royaume-Uni sur l'économie mondiale, suprématie qui contribua à l'apparition d'une aristocratie ouvrière et dont bénéficia le prolétariat britannique tout entier" ('The roots of British reformism no doubt lie in the history of a century of economic world supremacy, and the creation of a labour aristocracy, or even more generally, of an entire working-class which drew advantages from it'). Eric J. HOBSBAWM, 'Trends in the British Labour Movement since 1850" in Labouring Men. Studies in the History of Labour, Londres : Weidenfeld and Nicolson, 1986, 401 p.

${ }^{11}$ Pas un mot sur cette histoire commune dans Walter CITRINE, British Trade Unions, Londres : Collins, 1942, 48 p., ni dans Lionel BIRCH (dir.), The History of the TUC 18681968: A Pictorial Survey of a Social Revolution, Londres: General Council of the TUC, $1968,159 \mathrm{p}$.
} 
ensuite l'initiative du premier congrès national des syndicats britanniques ${ }^{12}$. On peut même dire que pendant quelques années, les deux histoires se confondent, comme en témoigne leur commun ancrage à Londres. Avant même la création du TUC, les militants londoniens furent ainsi à l'initiative d'une remarquable démonstration de solidarité internationale lorsqu'en 1867, leurs dons aux bronziers parisiens en grève permirent à ces derniers d'installer le conflit dans la durée et finalement d'obtenir la reconnaissance du syndicat par les employeurs. Au fil des années, des luttes menées à Genève, à Leipzig ou à New York bénéficièrent du même type de soutien moral et financier ${ }^{13}$. À l'instar de George Odger, qui de 1864 à 1867 cumula les fonctions de président de l'AIT et de secrétaire du Conseil londonien des syndicats, les tradeunionistes britanniques occupèrent donc dans la «Première Internationale » une place prépondérante. Aux yeux de Karl Marx, cheville ouvrière de l'AIT et ami personnel des principaux activistes londoniens, les trade-unions, en tant que premiers syndicats ouvriers de masse, n'étaient rien moins qu'un modèle d'organisation pour les travailleurs du monde entier. En réalité, le rôle pionnier que les syndicalistes britanniques auraient pu jouer dans les années 1870 vis-à-vis du mouvement ouvrier balbutiant en Europe ou en Amérique fut paradoxalement compromis par d'importantes conquêtes (élargissement du suffrage en 1867, reconnaissance accrue des syndicats en 1871) qui, confortant la ligne des dirigeants les plus modérés, poussèrent dans un même mouvement au repli sur l'arène nationale. Les trade-unionistes n'auraient-ils été des constructeurs enthousiastes de l'AIT que par souci d'autodéfense? Rétrospectivement, nombreux sont les historiens à avoir souligné les motivations essentiellement corporatistes et étroitement nationales des syndicalistes britanniques dans leur soutien occasionnel aux combats livrés sur le continent. Ils auraient moins cherché à bâtir un mouvement d'émancipation à vocation universelle qu'à se prémunir contre l'importation de «jaunes » en provenance de l'étranger et n'auraient trouvé pour ce faire d'autre moyen que d'encourager la syndicalisation chez les briseurs de grève potentiels ${ }^{14}$. Il n'est toutefois pas anodin qu'en 1871, lorsque Marx jugea que l'AIT avait fait son temps, il ait proposé de déplacer son siège à New York, comme si la manière la plus sûre de la mettre en sommeil était de la couper de ses racines londoniennes ${ }^{15}$.

Le TUC ne joua donc pas le rôle d'éclaireur que le père du socialisme scientifique avait espéré lui voir jouer. Construit sur les bases du syndicalisme Nouveau Modèle, dirigé par une «Junte » adepte du dialogue entre les classes sociales, il se cantonna jusqu'à la fin des années 1880 au rôle de défenseur des travailleurs qualifiés sur le marché du travail. L'organisation des travailleurs non qualifiés étant elle-même considérée comme vouée à l'échec et donc hors sujet sur

\footnotetext{
12 Jean SAGNES met un point d'honneur à le rappeler dans son Histoire du syndicalisme dans le monde des origines à nos jours, Toulouse : Privat (1994), pp. 180-182. C'est un récit allant dans le même sens que propose l'historien soviétique David RIAZANOV dans Marx et Engels ( $1^{\text {ère }}$ édition : 1923), Pantin : Les Bons Caractères, 2004, p. 226.

${ }^{13}$ Exemples mentionnés par Jonathan SAUNDERS dans Across Frontiers. International Support for the Miners' Strike 1984/85, Londres : Canary Press, 1989, 288 p.

${ }^{14}$ Les progrès techniques réalisés dans le dernier quart du dix-neuvième siècle donnèrent au problème un caractère particulièrement aigu, le passage de la voile à la vapeur et les progrès du chemin de fer permettant aux patrons d'importer des blacklegs beaucoup plus rapidement qu'aux premiers temps de la révolution industrielle.

${ }^{15}$ Le constat officiel de décès n'intervint qu'en 1876.
} 
le sol britannique, la question de la solidarité avec les travailleurs des autres pays ne figurait évidemment pas parmi les questions principales à l'ordre du jour lors des congrès annuels du mois de septembre. Quand elle était abordée, c'était tout au plus pour inciter les continentaux à suivre l'exemple britannique et pour leur souhaiter bon courage dans cette voie. Mais, moins exaltés que leurs prédécesseurs owenistes ou chartistes, les new model unionists n'avaient d'autre ambition qu'un certain aménagement du capitalisme national, auquel ils espéraient parvenir notamment par la collaboration avec le Parti libéral. Si Henry Broadhurst et ses compagnons se fendaient à l'occasion de déclaration de solidarité avec les travailleurs étrangers, ils se défendaient de partager les doctrines socialistes et révolutionnaires prisées sur le continent. L'écrasement de la Commune de Paris en mai 1871, puis l'interdiction des organisations se réclamant du socialisme par Bismarck en 1878 ne pouvaient que les conforter dans la justesse de leur choix : celui de l'accommodement, de la respectabilité, de la pondération - et de l'insularité.

Cette prudente mise à distance du mouvement ouvrier international se confirma lorsque celui-ci, renaissant de ses cendres, parvint en 1889 à reconstituer une association internationale, appelée bientôt par tous la « Deuxième Internationale ». Certes, quand celle-ci proposa de faire du $1^{\mathrm{er}}$ mai un rendez-vous d'action internationale pour la journée de huit heures, le TUC soutint l'initiative en organisant une manifestation monstre à Hyde Park, le dimanche 4 mai 1890. Mais ce ralliement ponctuel ne valait pas adhésion. Car la nouvelle internationale présentait un défaut majeur : celui de se fixer pour objectif la révolution socialiste. Or les leaders Lib Lab du TUC n'entendaient nullement compromettre leurs bons rapports avec les libéraux en se rangeant sous le drapeau rouge. Ils refusèrent donc avec constance de devenir partie prenante de l'Internationale ouvrière. Seule y adhéra une émanation du TUC, certes destinée à durer, à savoir le Parti travailliste, mais cela ne se fit qu'en 1908 et l'Internationale (qui ne s'était dotée d'un bureau qu'en 1900, onze ans après sa fondation, et était loin de former un bloc soudé) n'avait plus que quelques années à vivre $^{16}$. On aurait pu s'attendre à ce que les «nouveaux syndicats » de travailleurs non qualifiés apparus avec la vague de grèves de 1889-90, (dont les leaders, tels John Burns ou Will Thorne, se voulaient en rupture avec la modération du « vieux gang » et se revendiquaient du socialisme) essaient de peser, au sein du TUC, dans le sens d'un rapprochement avec la Deuxième Internationale. Mais Ben Tillett, le chantre par excellence de cette nouvelle radicalité, n'avait pas de mots assez durs pour «ces révolutionnaires continentaux bavards comme des pies et sans plus de cerveau que des rongeurs ${ }^{17}$. En effet, le new unionism se distinguait plus du trade-unionisme à l'ancienne par sa base sociale et par ses méthodes que par ses objectifs : il s'agissait en somme d'obtenir pour les general labourers, éventuellement au travers de grèves dures, des avancées économiques, mais pas de renverser l'ordre social. L'Internationale Socialiste, qui comptait en 1900 deux sections politiques en GrandeBretagne (la Social Democratic Federation d'une part, l'Independent Labour Party d'autre part), fit donc chou blanc auprès du mouvement syndical ${ }^{18}$.

${ }^{16}$ Jacques DROZ, Le Socialisme démocratique 1864-1960, Paris : Armand Colin, 1966, 360 p.

17 'The hare-brained chatterers and magpies of Continental revolutionists.' Cité dans Henry PELLING, A History of British Trade Unionism, op. cit., p. 119.

${ }^{18}$ G.D.H. COLE, A History of Socialist Thought. Vol. 3, The Second International 18891914, Londres : MacMillan, 1956, 1043 p. 
La défiance prévalut aussi envers le Secrétariat syndical international fondé en 1901, pour des raisons identiques : ses initiateurs ne cachaient pas leurs liens avec l'Internationale, ni leur volonté de placer l'action syndicale sur le terrain politique ${ }^{19}$. Seule la General Federation of Trade Unions, cette toute petite sœur du TUC, choisit d'y adhérer, un renfort bien insuffisant pour donner à l'organisme en question l'envergure internationale recherchée. Quand le Secrétariat, après quelques années en dents de scie, se reconstitua sous le nom de Fédération syndicale internationale (International Federation of Trade Unions), le TUC ne se départit pas de sa réticence coutumière, se contentant d'envoyer au congrès de refondation de 1913 un délégué et un seul, sous la pression de la fédération des mineurs, plus soucieuse que l'exécutif central de solidarité internationale ${ }^{20}$. Inutile de préciser que les tentatives répétées des syndicalistes révolutionnaires français de mettre sur pied une internationale syndicale ne parvinrent pas non plus à séduire le TUC ${ }^{21}$.

En somme, l'internationalisme des dirigeants du syndicalisme britannique consistait surtout en déclarations de solidarité de principe avec les ouvriers ou les militants victimes de la répression ailleurs dans le monde. Ils affirmèrent ainsi haut et fort leur soutien aux ouvriers russes au lendemain de la révolution de $1905^{22}$ et donnèrent de la voix, en 1909, contre l'emprisonnement sans procès de centaines de travailleurs espagnols par le régime d'Alphonse $\mathrm{XIII}^{23}$. Mais il était exclu pour eux de lier leur sort à une quelconque confédération internationale qui les aurait forcés à embrasser la cause du socialisme et de la révolution. Cela ne signifie pas, d'ailleurs, que les syndicalistes du rang ne se sentaient pas partie prenante du mouvement ouvrier international. De 1891 à 1914, le premier dimanche de mai devint pour eux, dans la plupart des grandes villes du pays, l'occasion rituelle de célébrer leur inscription dans cet ensemble. Les porte-parole des Trades Councils se lançaient parfois ces jours-là, surtout lorsqu'ils étaient de sensibilité socialiste, dans des diatribes enflammées sur la nécessité d'une alliance entre les travailleurs par-delà les mers et sur l'urgence d'établir un Commonwealth international. Le public répondait alors en chantant The Red Flag, voire La Marseillaise ou The International ${ }^{24}$. Mais il y avait un monde entre cet internationalisme sentimental assez largement répandu et la constitution de liens solides et durables avec des militants d'autres nationalités.

\section{Des coopérations réussies avec l'étranger}

Des collaborations sur le long terme virent pourtant le jour. Le rapprochement transnational auquel le TUC procéda avec le plus d'allant fut incontestablement avec l'American Federation of Labor (AFL), pour une raison simple: son président

\footnotetext{
${ }^{19}$ Jean SAGNES, Histoire du syndicalisme dans le monde ..., op. cit., pp. 184-185.

${ }^{20}$ Henry PELLING, A History of British Trade Unionism, op. cit., p. 148.

21 Constance BANTMAN, 'Internationalism without an International ? Cross-Channel Anarchist Networks, 1880-1914' in Magaly RODRIGUEZ GARCIA (dir.), Labour Internationalism: Different Times, Different Faces, Revue Belge de Philologie et d'Histoire, vol. 84, n 4, 2006, pp. 961-981.

${ }^{22}$ TUC, Annual Report 1906, p. 43.

${ }_{23}^{23}$ TUC, Annual Report 1909, p. 181.

${ }^{24}$ Eric J. HOBSBAWM, 'Birth of a Holiday: the First of May' in Uncommon People. Resistance, Rebellion and Jazz, Londres :Weidenfeld and Nicolson, 1998, pp. 113-127.
} 
Gompers l'avait fondé en 1886 sur le modèle du TUC lui-même, avec un attachement identique au niveau élevé de cotisation, à la rigueur dans la gestion et au pragmatisme. L'entente était donc possible entre des syndicalistes qui partageaient un même rejet du socialisme et qui concevaient leur fonction comme celle d'un groupe de pression auprès des élus de la nation ${ }^{25}$. À partir de 1894, les deux organisations prirent l'habitude d'échanger des «délégués fraternels» (fraternal delegates) à chacun de leurs congrès ${ }^{26}$. Lorsque le TUC, à partir de l'affaire Taff Vale, fit de l'élection de députés ouvriers indépendants des deux grands partis son cheval de bataille, l'entente cordiale resta de mise avec l'AFL, bien que les syndicalistes américains ne se soient pas engagés dans la même voie. Il faut dire que le Parliamentary Labour Party dont finit par accoucher le Labour Representation Committee (LRC) se proposait de poursuivre l'œuvre du TUC par des moyens institutionnels et graduels, qui demeuraient donc dans les limites du raisonnable aux yeux de Gompers ${ }^{27}$.

On se tromperait donc si on considérait que le syndicalisme britannique tourna le dos à la notion même de solidarité de classe internationale. Mais il la mit en œuvre sur un autre terrain que les militants de la CGT ou du SPD, privilégiant les revendications d'ordre strictement économique. Dans ce domaine, il connut des réussites spectaculaires qui sont souvent oubliées, peut-être parce que les alliances internationales les plus abouties ne furent pas l'œuvre du TUC en tant que tel, mais de certaines de ses fédérations, celles qui contribuèrent à la création des premiers «secrétariats professionnels internationaux » (SPI ou ITS, pour International Trade Secretariats). Les syndicalistes britanniques eurent en effet un rôle clé dans la formation de ces premiers véritables syndicats de métier internationaux. Rien d'étonnant à cela. Une trade union, par définition, est une union de métier et les Britanniques avaient sur le plan de l'organisation syndicale de type corporatiste une longueur d'avance sur leurs homologues étrangers. Comme il a déjà été signalé plus haut, ce fut sans doute plus par nécessité que par inclination naturelle que les tradeunionistes se firent les champions de l'unité prolétarienne et se résolurent à mettre leur expérience au service de leurs frères étrangers. Mais leur œuvre n'en fut pas moins colossale et durable. On les vit ainsi contribuer à la naissance de syndicats internationaux chez les cigariers (1889), les gantiers (1892), les métallurgistes (1893), les marins et les dockers (1896) ou encore les mouleurs (1898). On notera toutefois que sur la trentaine de SPI mis sur pied avant 1914, deux seulement avaient leur siège en Grande-Bretagne (celui des mineurs, fondé en 1890, et celui du textile, fondé en 1894), contre vingt-quatre en Allemagne ${ }^{28}$. Un signe supplémentaire d'une certaine réserve britannique?

\footnotetext{
${ }^{25}$ Henry PELLING, qui écrivit aussi sur le syndicalisme américain, souligne cette osmose dans son American Labor, Chicago : University of Chicago Press, 1961, 255 p.

${ }^{26}$ A l'occasion de ces grandes rencontres, Gompers ne tarit pas d'éloges sur des délégués britanniques d'obédience socialiste qu'il aurait difficilement tolérés au sein de l'AFL s'ils avaient été ses compatriotes, qu'il s'agisse de Keir Hardie ou de Tom Mann.

${ }^{27}$ Neville KIRK, 'Transatlantic Connections and American 'Peculiarities' : Labour Politics in the United States and Britain, 1893-1908' in Comrades and Cousins. Globalization, Workers and Labour Movements in Britain, the USA and Australia from the 1880s to 1914, Londres : Merlin Press, 2003, pp. 17-58.

${ }^{28}$ Jean SAGNES, Histoire du syndicalisme dans le monde ..., op. cit., p. 186.
} 
$\mathrm{Au}$ temps de la première mondialisation, la question de l'union avec les ouvriers étrangers ne concernait pas seulement ceux vivant outre-mer mais aussi ceux travaillant sur le territoire britannique lui-même. La première globalisation entraîna en effet un brassage sans précédent des populations et, sur le chemin qui menait des millions de personnes vers l'Amérique, la Grande-Bretagne constituait une étape presque obligée qui, pour certains, s'avéra l'aboutissement du périple ${ }^{29}$. La forte immigration constatée au Royaume-Uni entre 1880 et 1914, en grosse majorité composée de ressortissants juifs de l'Empire russe, augmenta le nombre de travailleurs sur le marché de l'emploi et, dans bien des secteurs, exerça une pression sur les salaires comme l'immigration irlandaise avait pu le faire dans les années $1840^{30}$. Pour éviter la surabondance de main d'œuvre, le TUC avait toujours encouragé ceux de ses adhérents qui étaient tentés par l'expérience à émigrer vers d'autres horizons. Mais à la toute fin du XIXe siècle, l'émigration ne constituait plus un vaccin suffisant contre la saturation du marché de l'emploi. Face à ce problème devenu incontournable, le TUC fut contraint de prendre le taureau par les cornes, mais il hésita toujours entre deux politiques : organiser les travailleurs étrangers les plus mal payés ou les exclure du marché du travail. En septembre 1895, le TUC compta pour la première fois parmi ses délégués un représentant des tailleurs juifs de Londres, qui bataillait notamment pour que le gouvernement envoie dans les ateliers de confection les plus durs des inspecteurs du travail parlant yiddish couramment $^{31}$. Mais dans cette même période, le TUC prit aussi officiellement position en faveur de l'aliens control voulu par le gouvernement conservateur ${ }^{32}$. Les trade-unionistes adoptèrent donc comme position de principe l'idée d'une intégration des travailleurs étrangers déjà présents sur le territoire par l'alignement des conditions de travail et de rémunération sur celles de l'ouvrier britannique. Mais ils étaient clairement réticents à de nouvelles arrivées. En 1905, quand le parlement adopta l'Aliens Act pour tenter d'endiguer l'immigration de masse, le TUC n'en prit pas moins parti pour la libre circulation des personnes, la dénonçant comme une entorse aux traditions britanniques d'hospitalité et de tolérance. Londres avait accueilli les réprouvés de 1848, elle pouvait bien accueillir les victimes des pogroms tsaristes ${ }^{33}$. Mais la traduction dans les actes de ces déclarations d'intention généreuses n'était pas si évidente. À vrai dire, les progrès étaient le plus souvent minimes tant que les travailleurs immigrés eux-mêmes ne prenaient pas en main leur sort collectif. Il revint à l'anarchiste juif Rudolf Rocker de syndiquer les ouvriers du textile de l'East End et du Yorkshire ${ }^{34}$, de même qu'il revint à l'ébéniste allemand Gustav Schmidt, dans le district de Hull, de regrouper les travailleurs du meuble au sein d'une grande Furnishing Trades Union ${ }^{35}$. De plus, toutes les fédérations composant le TUC ne parlèrent pas d'une même voix sur cette question et, face à la

\footnotetext{
${ }^{29}$ Nicholas EVANS, 'Indirect passage from Europe. Transmigration via the UK, 1836-1914', Journal for Maritime Research, Greenwich : juin 2001.

${ }^{30}$ Voir le chapitre 4 ('Newcomers, 1880-1914'), pp. 61-75 in James WALVIN, Passage to Britain. Immigration in British History and Politics, Harmondsworth : Penguin, 1984.

${ }^{31}$ Anne J. KERSHEN, Uniting the Tailors: Trade Unionism Amongst the Tailoring Workers of London and Leeds, 1870-1939, Ilford : Frank Cass, 1995, p. 86.

32 TUC, Annual Report 1892, p. 29.

${ }^{33}$ TUC, Annual Report 1905, p. 48.

${ }^{34}$ Rudolf ROCKER, The London Years, Londres : Anscome, 1956, 360 p.

${ }^{35}$ Raymond BROWN, Waterfront Organisation in Hull 1870-1900, Hull : University of Hull Publications, 1972, p. 49.
} 
concurrence directe des prolétaires étrangers, l'ouverture à l'autre, l'antiracisme et la volonté d'intégration par la syndicalisation ne furent pas toujours de mise.

\section{Les paradoxes révélateurs du syndicalisme maritime}

L'histoire du syndicalisme maritime avant la Première Guerre mondiale offre à la fois l'exemple le plus spectaculaire d'action ouvrière internationale et l'exemple le plus criant de xénophobie et de racisme ${ }^{36}$. On connaît les spécificités communes aux métiers de docker et de marin dans le Royaume-Uni d'avant 1914: un rôle crucial dans l'économie de la «reine des mers »; la pénibilité et la dangerosité extrême du travail; la précarité de l'emploi; la dureté des rapports avec les employeurs. Tel est l'arrière-plan d'une épopée syndicale qui, dès l'origine, prit un tour transnational. Rappelons-en ici les grandes étapes. Après une première vague de grèves en 1879-1881, il fallut attendre les grandes grèves de 1889, en particulier sur les docks de Londres et de Liverpool, pour que se reconstituent des réseaux syndicaux. Dans cette renaissance, le rôle de la solidarité internationale fut essentiel : la victoire ne fut alors acquise que parce que les dockers de Rotterdam refusaient de toucher aux bateaux en provenance ou à destination de GrandeBretagne et grâce aux 30000 livres envoyées par les syndicalistes australiens. Les années suivantes virent effectivement le rapport de force entre armateurs et new unionists se dérouler dans une arène européenne. Fondée dès 1890 en vue de la riposte autour des propriétaires de la $\mathrm{P} \& \mathrm{O}$, la British Shipping Federation sut mobiliser les armateurs de tous les pays pour organiser le cassage systématique des grèves. Dans la plupart des grands ports, des bataillons « jaunes » furent formés, qui permirent aux patrons du transport de se rendre mutuellement service. Il devint bientôt courant de voir une grève à Christiania ou à Hambourg brisée par l'intervention des free labourers de Hull ou, à l'inverse, de voir des dockers continentaux chargés, sous haute protection policière ou militaire, de «libérer » un port britannique paralysé par un conflit social. Cela rendait indispensable la création d'un syndicat international et le 27 juillet 1896, l'International Transport Workers Federation (ITF) vit le jour, avec un Britannique, Tom Mann, pour premier président et l'un de ses compatriotes, John Havelock Wilson, pour vice-président ${ }^{37}$. Lorsque Mann passa la main en 1901, l'organisation comptait des sections non seulement en Grande-Bretagne, mais aussi en France, en Belgique, aux Pays-Bas, en Allemagne et au Danemark ${ }^{38}$. Dans le bras de fer en cours, les armateurs britanniques pouvaient moins que jamais permettre aux patrons de chaque pays de faire cavalier seul et ils fondèrent en 1907 une International Shipping Federation. Impuissante à éviter les défaites en série des années 1893-1907, 1'ITF finit par faire reculer le patronat du transport en orchestrant en juin 1911 une «grève

\footnotetext{
${ }^{36}$ Cette enfance contrastée du 'T\&G' est retracée par Ken COATES et Tony TOPHAM dans The Making of the Transport and General Workers' Union: The Emergence of the Labour Movement 1870-1922, Oxford : Blackwell, 1991, 909 p.

${ }^{37}$ Voir la brochure de Tom MANN éditée par The Clarion en 1897 : The Position of Dockers and Sailors in 1897 and the International Federation of Ship, Dock and River Workers, $14 \mathrm{p}$.

${ }^{38} \mathrm{Y}$ étaient également affiliés des cheminots de toute l'Europe du nord-ouest, ainsi que d'Espagne et d'Australie. Frank BROEZE, 'Militancy and pragmatism: an international perspective on maritime labour 1870-1914', International Review of Social History, 1991, vol. 36, p. 189.
} 
internationale des gens de mer » qui se révéla irrésistible, en particulier grâce au rôle moteur de la National Transport Workers Federation (NTWF) mise sur pied au Royaume-Uni au cours de l'année précédente ${ }^{39}$. Les marins des plus grands ports britanniques, belges et néerlandais, souvent suivis par les dockers, obtinrent alors ce qu'on leur avait toujours refusé : la reconnaissance des syndicats comme interlocuteurs légitimes et des avancées substantielles en matière d'horaires et de salaires. À la mondialisation capitaliste, l'ITF eut donc l'audace de répondre par une mondialisation des revendications et des luttes. On remarquera que le répertoire d'action utilisé en 1911 (grèves de solidarité, action directe de masse, sabotage voire émeutes) était lui-même d'inspiration étrangère, librement adapté des méthodes expérimentées depuis 1905 par les cégétistes en France ou par les Wobblies aux États-Unis $^{40}$. Ces appropriations, par choc en retour, modifièrent jusqu'en 1914 la façon dont le mouvement ouvrier international percevait le syndicalisme britannique : ceux qui la veille avaient fustigé son embourgeoisement saluaient désormais sa combativité voire l'érigeaient en modèle ${ }^{41}$.

Parrains de ce qui fut probablement la première grève internationale d'une aussi grande envergure, la NTWF et surtout la National Seamen and Firemen's Union (NSFU) furent pourtant à l'origine, trois ans plus tard, d'une campagne contre le «Péril Jaune» aux accents ouvertement racistes. On a souligné plus haut que la mondialisation des flux humains avait pu conduire, en particulier dans les périodes de crise, à un engorgement du marché du travail. Si ce phénomène frappa de plein fouet les marins, il ne les mit pas en concurrence avec des travailleurs immigrés au Royaume-Uni en tant que tels, mais avec des ouvriers étrangers employés de plus en plus massivement dans la marine marchande britannique à partir de 1890 : les «Lascars» (originaires du sous-continent indien) et surtout les «Chinois» (originaires d'Asie du Sud Est) ${ }^{42}$. Ces Asiatic Seamen étaient payés moitié moins cher que les marins ou les chauffeurs britanniques, ce qui était évidemment source de chômage occasionnel pour ces derniers. La philosophie du «Nouveau Syndicalisme », moins corporatiste que celle du TUC des origines, aurait pu impliquer une main tendue aux Lascars et aux Chinamen. La NSFU semble d'ailleurs avoir essayé, dans un premier temps, de les amener au syndicat ${ }^{43}$. Mais en avril 1914, elle engagea une campagne sur la nécessité de contraindre les armateurs britanniques à réserver le travail aux marins britanniques, qui rencontra un vrai succès auprès de la profession. Exerçant un métier par définition nomade et fréquentant un milieu portuaire par définition cosmopolite, on aurait pu croire les gens de mer plus allergiques que d'autres aux propos xénophobes et racistes. Mais le caractère international de leur activité, s'il les mettait en position exceptionnellement favorable pour s'allier à leurs homologues d'autres nationalités,

${ }^{39}$ A cette grève internationale ne prirent toutefois part ni les marins français, ni les marins allemands, ni ceux d'Amsterdam.

${ }^{40}$ Robert J. HOLTON, British Syndicalism 1900-1914. Myths and Realities, Londres : Pluto Press, 1976, 232 p.

${ }^{41}$ Jean-Louis AUDUC, Le mouvement syndical anglais à travers la presse syndicaliste française 1911-1914, mémoire de maîtrise, Université Paris I, 1973, 145 p.

${ }^{42}$ Des petites communautés apparurent certes avant 1914 dans certains ports du pays, mais elles ne s'enracinèrent et ne grossirent vraiment qu'après la guerre.

${ }^{43}$ Arthur MARSH et Victoria RYAN, The Seamen : A History of the National Union of Seamen, Oxford : Malthouse, 1989, 357 p. 
les condamnait aussi à vendre leur force de travail sur un marché surexposé où l'allié d'un jour pouvait, le lendemain, vous ôter le pain de la bouche. L'ITF avait dans une certaine mesure permis de souder les marins européens. Mais comment organiser des ouvriers dont on ne parlait pas du tout la langue et que la doxa de l'époque tenait pour racialement inférieurs, incompétents et foncièrement déloyaux ? Selon J.H. Wilson, le patron de la NSFU, l'option la plus réaliste ne pouvait être qu'un compromis avec les employeurs excluant les «jaunes» de l'embauche ${ }^{44}$. L'agitation qui se poursuivit sur le sujet jusqu'au déclenchement de la guerre devait porter quelques fruits, la Shipping Federation infléchissant quelque peu sa politique à l'embauche pour éviter un affrontement aussi sévère qu'en 1911.

Episode considéré aujourd'hui comme honteux dans l'épopée du T\&G, la campagne de 1914 n'a pourtant rien d'un dérapage. Elle est au contraire caractéristique du positionnement du syndicalisme britannique dans la première mondialisation en ce qu'elle révèle la nature fondamentalement pragmatique, plus que principielle, de l'internationalisme revendiqué en 1911. Certes, parmi les animateurs du mouvement, on trouvait bien un Tom Mann, dont l'antiracisme intransigeant allait de pair avec la conviction que l'action directe du prolétariat sur un plan international était la voie la plus sûre vers le renversement du capitalisme à l'échelle mondiale. Mais ces conceptions restèrent très minoritaires parmi les tradeunionistes britanniques, même au plus fort du Great Labour Unrest. Pour les principaux dirigeants des syndicats du transport, le recours à la solidarité voire à la grève internationale était d'abord une arme en vue de contraindre le patronat national à la discussion. Les objectifs d'un James Sexton restaient conformes à ceux défendus depuis ses premiers pas par le TUC: reconnaissance des syndicalistes comme partenaires sociaux, établissement d'instances de négociation permanentes, intervention de l'État dans les conflits éventuels, droit de regard syndical sur les modalités d'embauche. Comment obtenir satisfaction sur ce terrain-là était ensuite une question tactique. La défense des intérêts matériels des ouvriers britanniques pouvait justifier de recourir, selon les circonstances, à l'action en commun avec les ouvriers étrangers ou à leur exclusion. L'espoir demeurait alors qu'une bonne entente entre les classes sociales à l'échelle des îles Britanniques était possible, une aspiration que les trade-unionistes partageaient avec les tenants du libéralisme.

\section{La mondialisation économique et ses enjeux sociaux : les lunettes libérales}

L'expansion de la révolution industrielle hors de Grande-Bretagne au cours de la seconde moitié du XIXe siècle mit donc rapidement les trade-unionistes face à l'obligation de se trouver des alliés à l'étranger. Mais quelle vision avaient-ils du processus économique qui les plaçait devant ces nouveaux défis ? Pour s'orienter dans cette société en mutation, aux frontières sans cesse élargies, les syndicalistes britanniques ne semblent pas avoir ressenti le besoin d'élaborer une conceptualisation propre. Il faut dire que, si un certain cosmopolitisme allait de soi dans les classes dominantes, le vécu des prolétaires victoriens était par la force des

\footnotetext{
${ }^{44}$ Ken COATES et Tony TOPHAM, The Making of the Transport and General Workers' Union: The Emergence of the Labour Movement 1870-1922, op. cit., pp. 541-546.
} 
choses avant tout local ou régional et le militant syndical, dans ses combats quotidiens à l'échelle de l'entreprise ou de la ville, pouvait fort bien défendre ses camarades avec efficacité sans connaître tous les rouages d'un capitalisme en train de se mondialiser à grande vitesse $e^{45}$. La globalisation était un phénomène sans doute bien abstrait pour les travailleurs du rang et l'expérience d'un permanent de fédération ou d'un membre du Comité parlementaire du TUC, habitué non seulement aux couloirs de Westminster mais aux contacts internationaux, n'avait rien à voir avec celle du syndiqué de base. Chaque prolétaire n'en était pas moins conscient, surtout s'il travaillait dans une grande ville, dans la grande industrie ou dans un port, que le Royaume-Uni commerçait avec la terre entière et qu'il la dominait. À défaut d'une théorie de la mondialisation - le vocable n'entre d'ailleurs dans le langage courant qu'à la fin du XXe siècle - , chacun avait donc en tête ses points de repère, glanés ça et là, lui permettant de faire sens de l'univers où il évoluait. Cet ensemble de représentations mentales formait donc un tout éclectique, à l'ossature solidement libérale. Mais entre 1868 et 1914, cette vision plutôt positive de la globalisation se vit de plus en plus contestée à mesure que l'hégémonie britannique était ébranlée. Dans les années 1890, la concurrence des industries étrangères fut en effet invoquée de plus en plus souvent pour imposer aux travailleurs une série de régressions et les arguments des protectionnistes et des socialistes quant à la meilleure manière de défendre la condition ouvrière dans ce contexte inédit eurent un certain impact sur les milieux syndicaux - contraignant les libéraux à une profonde révision doctrinale pour ne pas perdre l'oreille de l'électorat ouvrier.

\section{Le credo libre-échangiste}

En 1868, quand le TUC voit le jour, le libre-échange (Free Trade) fait presque l'unanimité au Royaume-Uni. C'est que depuis longtemps déjà, un consensus existe entre patronat et salariat à propos de ses bienfaits. L'abolition des lois sur le grain (Corn Laws) en 1846, conquise de haute lutte par la double pression des industriels et du mouvement ouvrier, symbolise on ne peut mieux cette conjonction d'intérêts : pour l'ouvrier, elle est synonyme de pain enfin bon marché ; pour l'employeur, de frais salariaux réduits. Dans les années qui suivent, lorsque la Grande-Bretagne s'impose comme « l'atelier du monde », c'est tout naturellement sous la bannière du libre-échange qu'elle inonde le marché international de ses produits manufacturés. Lorsqu'à l'occasion se dressent des barrières devant le commerce britannique, la canonnière intervient, et le «libre-échange »d'étendre son emprise $e^{46}$. À ce jeu, la bourgeoisie britannique s'enrichit considérablement, mais une fraction importante du prolétariat profite également de cette domination sans partage : les plus qualifiés des travailleurs voient ainsi leur niveau de vie augmenter par rapport aux premiers temps, il est vrai effroyables, de la révolution industrielle et, au fil du siècle, le plus

\footnotetext{
45 Ainsi que Tony Pilch ou Paul Mason l'ont récemment rappelé, l'émergence de l'internationalisme ouvrier ne coula pas de source. La «mondialisation par en bas », véritable passage dans une autre dimension, se fit en quelque sorte au forceps.

${ }^{46}$ Les « guerres de l'opium » menées contre la Chine (en 1839-1842, puis en 1856-1860) sont les exemples les plus connus de cette politique.
} 
gros de la classe ouvrière voit son espérance de vie augmenter ${ }^{47}$. Au cours des vingt années qui séparent l'échec du chartisme et la fondation du TUC, new model unionists et hommes politiques libéraux se retrouvent donc autour d'un 'midVictorian compromise' qui marque durablement la perception trade-unioniste de l'économie internationale: pour les «aristocrates ouvriers» qui jettent les fondations du TUC, les bénéfices que le libre-échangisme a apportés à la condition ouvrière vont de soi. Comptant sur l'appui du Parti libéral pour obtenir le vote par les Communes de lois favorables au monde du travail, gradualistes et non révolutionnaires, les George Howell et autres Henry Broadhurst adoptent naturellement la philosophie des éléments réformateurs de l'élite, et notamment leur regard optimiste sur cette mondialisation économique dont le capital britannique est alors le principal protagoniste ${ }^{48}$.

Cette confiance dans les vertus du libre-échange se retrouve encore à la veille de la Première Guerre, par exemple sous la plume de Fred Maddison, syndicaliste des chantiers navals de Hull et ex-président du Trades and Labour Council local, que le Parti libéral a choisi par deux fois (1892 et 1895) de présenter comme candidat à la députation. En 1913, dans une tribune intitulée «La Mission du Libéralisme », il s'adresse ainsi à son public ouvrier :

Le libre-échange a permis la création de richesse sans entraves, sans aucune de ces restrictions artificielles que constituent les tarifs douaniers. (...) Sur la table du travailleur, on trouve aujourd'hui une variété de nourriture bien plus grande qu'à l'époque de son grandpère. La vérité est que cette heureuse évolution est due directement aux fantastiques progrès réalisés dans les transports, c'est-à-dire à notre marine marchande. Mais c'est le libre-échange qui a permis notre suprématie navale et qui lui permet de se maintenir. L'importation de marchandises en provenance de l'étranger est peu onéreuse et le consommateur britannique en profite, tandis que les tarifs douaniers, dans les pays protectionnistes, privent les travailleurs de certains de ces avantages. Le libre-échange nous ouvre les portes du monde entier et le transforme en un immense marché où nous approvisionner à volonté. En ce sens, il agit vraiment comme un distributeur de richesse; il accroît le pouvoir d'achat des salaires. ${ }^{49}$

47 Eric J. HOBSBAWM, Industry and Empire. From 1750 to the Present Day, Harmondsworth : Penguin (1 $1^{\text {ère }}$ édition : 1968), 1972, 384 p. Voir aussi Stéphane LEBECQ, Fabrice BENSIMON, Frédérique LACHAUD et François-Joseph RUGGIU, Histoire des îles britanniques, Paris : PUF, 2007, pp. 644-652.

${ }^{48}$ Neville KIRK, The Growth of Working Class Reformism in Mid-Victorian England, Urbana et Chicago : University of Illinois Press, $1985,369 \mathrm{p}$.

49 Frederick MADDISON, 'The Mission of Liberalism', Central Hull Liberal Bazaar. Festival of Empire 1913, pp. 82-83. 'Free Trade has enabled wealth to be created without let or hindrance so far as artificial restrictions in the form of tariffs are concerned. (...) On the table of the workman to-day there is a far greater variety of food than was known to his grandfather. It is true that this is immediately due to the wonderful increase in transit facilities - that is, to our mercantile marine. But Free Trade created and maintains our shipping supremacy. The British consumer gets the advantage of cheap carriage of goods from abroad, whereas in Protectionist countries tariffs deprive the workers of some of these advantages. 
À lire Fred Maddison, le libre-échange est donc la panacée universelle, la garantie que la suprématie du Royaume-Uni sur le commerce maritime va durer et que le monde va continuer à être, pour le travailleur britannique, une corne d'abondance. Une vision différente de la mondialisation est toutefois évoquée ici en négatif, qui a gagné du terrain depuis la fin des années 1880: celle des protectionnistes.

\section{Des tentations protectionnistes ?}

L'adhésion traditionnelle des entrepreneurs au libre-échange est en effet remise en cause lorsque le Royaume-Uni commence à voir sa domination sérieusement menacée par les rivaux états-unien et allemand. Autant la bourgeoisie britannique tient à pouvoir exporter à sa guise, autant elle voit d'un mauvais œil les importations de produits manufacturés en provenance du continent ou d'outreAtlantique. Faut-il laisser ainsi le marché national grand ouvert et accepter de céder du terrain à la concurrence ? On songe de plus en plus à ériger des barrières douanières et à protéger l'industrie nationale en taxant les produits importés, à la manière des Américains, des Allemands ou des Français, mais on craint qu'une telle mesure n'entraîne une véritable guerre des taxes susceptible de nuire durablement aux exportations britanniques. Ces dilemmes qui taraudent patrons et hommes d'État font discuter toute la nation et s'invitent jusqu'aux congrès du TUC ${ }^{50}$. Au tournant du XXe siècle (entre approximativement 1895 et 1905), c'est en effet au nom de la concurrence internationale grandissante que les patrons britanniques remettent en cause le 'mid-Victorian compromise' et se lancent dans une offensive générale contre nombre d'acquis ouvriers, des instances de négociations au droit de grève, du niveau des salaires à la reconnaissance des qualifications. Les arguments invoqués sont les suivants : étant donnée la faiblesse des salaires à l'étranger, les produits britanniques ne seraient plus compétitifs et il n'existerait que deux manières de sauver l'industrie nationale et les emplois, à savoir imposer lourdement les importations ou diminuer les salaires ${ }^{51}$. Des voix protectionnistes se font entendre dès les années 1880, mais la campagne la plus vigoureuse est menée en 1903 par Joseph Chamberlain, ce transfuge du Parti libéral qui parvient, en 1905, à faire de la réforme des tarifs douaniers la doctrine officielle du Parti conservateur. Il la présente

Free Trade opens up the whole world as a market in which to buy the things we want. In this way it does act as a distributor of wealth; it adds to the purchasing power of wages'.

${ }^{50}$ Les partisans du protectionnisme prétendaient défendre les principes du «commerce équitable » (fair trade), une notion qui n'a plus du tout le même sens aujourd'hui. La survie de l'économie traditionnelle indienne n'était pas le premier des soucis des fair traders de la Belle Époque.

${ }^{51}$ Des années 1980 à nos jours, cette argumentation a été souvent reprise par les milieux patronaux. Le sociologue Richard Hyman y voit une façon d'utiliser le phénomène bien réel de la mondialisation pour en faire un mythe démobilisateur, susceptible de préparer les salariés à se résigner par avance à tous les sacrifices. Un des leitmotivs de l'époque actuelle est le chantage à la délocalisation en direction des pays à très bas salaires, dont Hyman rappelle le peu de fondement : dans les pays les plus industrialisés, les délocalisations ne sont responsables chaque année que d'une part infime de l'ensemble des licenciements et elles se font dans plus de trois quarts des cas en direction d'un pays de la Triade, pas du Tiers-Monde. Annie FOUQUET, Udo REHFELDT et Serge LE ROUX (dir.), Le Syndicalisme dans la mondialisation, op. cit., p. 150. 
comme le seul garde-fou contre un recul du niveau de vie des classes populaires et sa Tariff Reform League se dote rapidement d'une branche ouvrière, la Trade Union Tariff Reform Association. Cette dernière insiste sur les sommes importantes que la réforme permettrait de réunir en vue d'assurer une véritable sécurité sociale, le tout sans mettre à contribution les salaires mais seulement les compagnies étrangères ${ }^{52}$.

Pourquoi les trade-unionistes, à de rares exceptions près, ne suivent-ils pas le virage protectionniste que prennent aux alentours de 1900 un certain nombre d'industriels dans l'espoir de juguler une globalisation qui se retourne contre eux et dont ils assurent que les prolétaires vont pâtir ? Il y a la raison économique : la classe ouvrière reste attachée à son big loaf et, dans la mémoire collective, le protectionnisme évoque inévitablement le pain hors de prix des Hungry Forties. Il y a surtout, au début du XXe siècle, les raisons sociales et politiques. Aux yeux de la plupart des syndicalistes, le protectionnisme est la doctrine d'un Parti conservateur auquel ils n'ont aucune raison de faire confiance, non seulement à cause de son attachement de toujours à la hiérarchie sociale, mais à cause de l'atteinte au droit de grève portée en 1901 par le jugement des Lords dans l'affaire Taff Vale. Si ce n'est dans des secteurs très spécifiques, la volonté protectionniste de réguler les échanges n'aura donc guère de prise sur les réseaux syndicaux ${ }^{53}$. Ce n'est pourtant pas faute d'efforts de la part des conservateurs pour les enrôler sous leur bannière, ainsi qu'en témoigne le texte 'Tariff Reform and the Workman', écrit en 1913 par le président de la Tariff Reform League de Hull, comme en écho à l'évangile libre-échangiste cité plus haut :

Il est plutôt satisfaisant de noter que (...) l'on fait petit à petit baisser le temps de travail et que l'on reconnaît enfin la nécessité d'un niveau décent pour les salaires. Mais ces nobles considérations sont vite oubliées par le gouvernement, lorsqu'il accepte l'importation sans restriction de produits manufacturés en provenance de l'étranger, même qu'il est de notoriété publique qu'ils sont fabriqués dans les conditions les plus cruelles.

Si l'on accordait enfin à la politique fiscale de notre pays toute l'attention qu'elle mérite, cette anomalie serait corrigée et le travailleur britannique pourrait profiter pleinement des nombreux acquis pour lesquels il a combattu avec tant d'acharnement.

On peut raisonnablement se poser les questions suivantes : « Le sort de l'ouvrier est-il satisfaisant sous le régime du libre-échange? Alors que le commerce est en pleine expansion, l'ouvrier reçoit-il la part qui lui est due ? » La réponse nous est donnée par la vague de conflits sociaux qui a récemment secoué le pays. (...) Le seul remède est la réforme des tarifs douaniers, car elle garantira de meilleurs logements, des salaires plus élevés, la régularité de l'emploi et une meilleure entente entre le

\footnotetext{
52 John BELCHEM, Class, Party and the Political System in Britain 1867-1914, Oxford : Blackwell (1 ${ }^{\text {ère }}$ édition : 1990), 1995, p. 29-32.

${ }^{53}$ K.W.W. AIKIN, The Last Years of Liberal England 1900-1914, Londres : Collins (1 ${ }^{\text {ère }}$ édition : 1972), 1989, pp. 37-43.
} 
Capital et le Travail. ${ }^{54}$

On notera avec quel aplomb l'auteur présente la réforme des tarifs douaniers comme un moyen de punir l'exploitation sans scrupule de la main d'œuvre à l'étranger, avec quelle audace aussi il salue la légitimité de la vague de grèves en cours, cette pierre bienvenue dans le jardin des libéraux. Mais il était difficile pour le lecteur ouvrier de prendre ces déclarations de bonnes intentions au pied de la lettre et de ne pas y voir double jeu et démagogie. Les Tories ne s'étaient pas montrés si scrupuleux en 1904 lorsque les compagnies minières d'Afrique du Sud, avec leur bénédiction, avaient fait venir de Chine une main d'œuvre si mal payée qu'on ne parla plus, pendant quelques mois, que du Chinese slavery scandal ${ }^{55}$. Les syndicalistes n'étaient pas non plus sans connaître les prises de position systématiquement anti-grève des conservateurs. Tout en s'interrogeant sur les conséquences sociales possibles d'un rattrapage de l'économie britannique par ses rivales, les trade-unionistes n'embrassèrent donc que minoritairement l'option protectionniste.

\section{Le travaillisme dans les pas du néo-libéralisme}

$\mathrm{Au}$ cours de la dernière décennie du XIXe siècle, malgré la croissance phénoménale du commerce britannique, les trade-unionistes se rendent à l'évidence : on ne peut plus se contenter de faire confiance au libre jeu des échanges internationaux pour voir le sort des classes laborieuses s'améliorer. Aux problèmes posés par la nouvelle configuration économique mondiale, le mouvement socialiste apporte une réponse originale, en renvoyant dos à dos libre-échangistes et protectionnistes. Tel est le propos de la brochure Free Trade, Tariff Reform and Socialism, signée T.D. Benson et éditée en 1907 par l'Independent Labour Party (ILP). En 1909, la Clarion Press publie deux brochures en forme de diptyque, John Bull and Doctor Free Trade et John Bull and Doctor Protection, qui décrivent ces médecins comme deux charlatans, au service exclusif des classes dominantes ${ }^{56}$. La seule alternative aux poudres de perlimpinpin proposées par les uns et les autres

\footnotetext{
${ }^{54}$ H. FELDMAN, 'Tariff Reform and the Workman', West Hull Grand Imperial Fête and Unionist Bazaar 1913, p. 139. 'It is rather satisfactory to note that (...) the hours of labour are gradually being reduced and the justice of a living wage recognised, yet this high moral principle is departed from in dealing with the admission of manufactured goods from foreign countries and no restriction imposed, even where it is known that they are produced under the most cruel conditions. If a carefully studied consideration were given to the Fiscal Policy of this country, this anomaly would be dealt with and the British workman would get the full benefit of the many advantages which he has so strenuously fought to secure. One can reasonably ask these questions: "Is the lot of the toiler satisfactory under Free Trade ?" "Is he getting a fair share of the boom in Trade ?" The recent industrial unrest all over the country provides the answers. (...) Tariff Reform will come to the rescue in the form of improved housing, higher wages, regularity of employment, and a better understanding between Capital and Labour'.

${ }_{55}^{5}$ K. W. W. AIKIN, The Last Years of Liberal England 1900-1914, op. cit., pp. 43-48.

${ }^{56}$ L'auteur, R.B. Suthers, voit comme différence principale entre les deux médecins le fait que leurs thérapies s'adressent à des branches différentes des classes riches, le protectionnisme correspondant aux intérêts des propriétaires fonciers, le libre-échangisme à ceux des industriels.
} 
serait la collectivisation des moyens de production à l'échelle du pays : Britain for the British, selon les termes de Robert Blatchford. Ce schéma, qui propose moins une refondation de la mondialisation sur de nouvelles bases qu'une voie anglaise vers le socialisme, ne pénètre que marginalement les milieux syndicaux ${ }^{57}$. Mais c'est bien la crainte d'une poussée socialiste chez les ouvriers et la peur d'une explosion sociale plus violente encore que celle de 1889 qui oblige les libéraux des années 1890 à renouveler leur programme économique et social. Loin de s'en remettre à la seule main invisible du marché et à l'expansion «naturelle» du capitalisme britannique, les libéraux se veulent désormais réformateurs, ambitionnant de mettre fin aux conflits sociaux par l'institution d'un dialogue social obligatoire au sein des branches et des entreprises, ainsi que par une politique audacieuse de protection contre le chômage, les accidents et la vieillesse. Dans l'univers impitoyable du commerce mondial, ils avancent l'idée que l'État doit jouer un rôle régulateur ${ }^{58}$.

Comment se positionnent les trade-unionistes face à cette mutation du Parti libéral ? Dans cette nouvelle période, où le patronat exige de sa main d'œuvre qu'elle consente à se serrer la ceinture pour assurer la compétitivité des produits britanniques sur le marché mondial, l'idée que les trade-unionistes se font de la globalisation économique ne peut être tout à fait la même qu'en 1868 : tout en rejetant la tentation protectionniste et en réaffirmant leur attachement au libreéchange, ils se veulent désormais critiques du laisser-faire. À l'unisson des New Liberals, le TUC axe son discours sur la nécessité de négociations collectives entre patrons et syndicats et sur le refus des méthodes "américaines » (c'est-à-dire violemment antisyndicales) que prônent une majorité de fédérations d'employeurs. Sur la meilleure manière de contrer les effets néfastes de la concurrence économique internationale, les syndicalistes britanniques ne se distinguent des néo-libéraux que par leur réticence à une intervention étatique trop poussée. Par attachement à leur autonomie, ils refusent dans leur majorité que la protection sociale dépende de caisses gérées par l'État, préférant qu'elle se fasse sur la base du volontariat et par le canal des mutuelles ouvrières. Au début du XXe siècle, là où le libéralisme s'adapte en se renouvelant à la nouvelle donne mondiale, le TUC semble paradoxalement presque conservateur. Le Parliamentary Labour Party qui naît en 1906 sur les bancs des Communes n'est guère plus imaginatif sur ce terrain et les syndicalistes passées à l'heure travailliste ne développent pas une vision originale de l'économie internationale ni de la société. En apparence, à partir de 1901, ils ont pris leurs distances avec le Parti libéral, en se ralliant enfin à l'objectif d'une représentation ouvrière indépendante au sein du Parlement. Mais sur les questions économiques et sociales, ils ne font que reprendre, avec un peu plus d'entrain que le TUC, certains thèmes des néo-libéraux. Les militants syndicaux influencés par l'ILP soutiennent

${ }^{57}$ Voir la conclusion du chapitre 'How to keep foreign trade', pp. 108-109 dans Robert BLATCHFORD, Britain for the British (Londres : Clarion Press, 1902) : «Le commerce de ce pays est handicapé, mais il n'est pas handicapé par les pauvres travailleurs : il est handicapé par les riches oisifs, dont les rentes et les profits énormes empêchent l'Angleterre de rester la première sur le marché mondial » ('The trade of this country is handicapped; but it is not handicapped by the poor workers, but by the rich idlers, whose enormous rents and profits make it impossible for England to retain the foremost place in the markets of the world').

${ }^{58}$ L'adjectif «néo-libéral » n'est donc pas né avec les théories de Friedrich Hayek et de Milton Friedman. Les premiers «néo-libéraux » défendaient des conceptions régulatrices, étatistes et quasi-corporatistes, diamétralement opposées à celles qu'élaborerait l'école de Chicago. 
ainsi l'idée que, si la splendeur britannique n'est plus ce qu'elle était, la solution pour maintenir le niveau de vie du peuple n'est pas d'abaisser les salaires mais de taxer les plus grandes fortunes, une proposition émise également par Lloyd George et qu'il matérialisera avec son People's Budget de 1910.

Là où la fin de l'hégémonie britannique sur le commerce international aurait pu pousser les trade-unionistes dans les bras de la Deuxième Internationale ou des Tariff Reformers, le Parti libéral sut donc négocier le virage et les garder dans son orbite. Conscient que son retour aux affaires dépendait de ces travailleurs urbains qui avaient accédé au droit de vote en 1885, il axa sa campagne de 1906 sur deux thématiques susceptibles de capter les voix ouvrières (la promesse de réformes sociales et le rejet du protectionnisme), un choix bien vu et qui s'avéra payant. De 1906 à 1914, tant le TUC que le Parti travailliste et le mouvement coopératif restèrent à la remorque des gouvernements libéraux. Avec le recul, on ne peut d'ailleurs que constater que la radicalisation des années 1911-1914 elle-même, malgré les solidarités transnationales mises en jeu, ne marqua pas une rupture dans l'appréhension de la globalisation par la classe ouvrière et par ses militants : si on se syndiqua alors en masse, si on se mit plus fréquemment en grève, ce ne fut moins pour «renverser le système » que pour réclamer «sa part du gâteau ». De ce point de vue, il est significatif qu'à la veille de la guerre, l'immense majorité des ouvriers titulaires du droit de vote, loin d'aspirer à une révolution internationale, continuaient de voter pour l'un ou l'autre des deux grands partis « orthodoxes». La grille de lecture la plus commune chez les trade-unionistes resta donc celle véhiculée par leur état-major national, à savoir une grille d'essence libérale. Si on considère l'idéologie libérale comme l'expression même des intérêts de la bourgeoisie britannique à l'ère victorienne, on pourrait s'étonner de la voir partagée si largement dans les rangs salariés. Mais ce serait oublier qu'une idéologie produite par la classe dominante ne devient idéologie dominante qu'en tant qu'elle parvient à se diffuser dans l'ensemble de la société, en offrant un modèle de compréhension crédible de la réalité sociale. Le libéralisme offrait un tel modèle. Malgré des campagnes protectionnistes répétées, il resta dans «dans l'air du temps » jusqu'à la guerre et les adhérents au TUC ne furent pas les membres les moins enthousiastes de ce qu'un historien a récemment appelé la «nation du libre-échange ${ }^{59}$. Malgré des crises à répétition, la conviction existait chez ceux qui se targuaient de représenter les intérêts des working men que le dynamisme de l'économie britannique, même concurrencée, pouvait assurer à tous, dans le cadre des rapports de production existants, un niveau de vie convenable. L'expansion et la consolidation de l'Empire britannique entre 1870 et 1914 furent bien sûr pour beaucoup dans ce sentiment de confiance. Si le monde syndical n'emboîta pas le pas au Chamberlain protectionniste de 1903-1905, on pourrait presque considérer que c'est par fidélité au Chamberlain libéral des années 1880, dont le «radicalisme» teinté d'impérialisme avait fait florès chez les trade-unionistes ${ }^{60}$. Revendiquant, sur le plan intérieur, le suffrage universel masculin, la réforme agraire et le socialisme municipal, en même temps qu'il prônait, sur le plan extérieur, l'exploitation par la race anglo-saxonne des plus

\footnotetext{
${ }^{59}$ Frank TRENTMANN, Free Trade Nation. Commerce, Consumption and Civil Society in Modern Britain, Oxford : Oxford University Press, 2008, 450 p.

${ }^{60}$ Voir le livret Radical Songs for Working Men imprimé par Michael Waller pour le Radical Club de Hull, en soutien à la candidature de l'ouvrier N.B. Billany dans l'élection générale de 1885 .
} 
vastes territoires possibles, comme moyen infaillible d'apporter aux masses laborieuses le mieux-être dont elles avaient besoin, son « libéralisme radical » avait laissé une empreinte durable. C'est à cette liaison dangereuse entre trade-unionisme et empire qu'il convient maintenant de s'intéresser.

\section{Le trade-unionisme sur les ailes de l'Empire : splendeurs et misères d'une expansion}

$\mathrm{Au}$ cours des dix dernières années, l'intérêt renouvelé des historiens britanniques pour l'expérience impériale a permis de rappeler ses conséquences humaines catastrophiques pour les peuples colonisés. Oppression, exploitation : le tableau dressé est globalement négatif. Mais on en oublierait presque que pour les syndicalistes britanniques des époques victorienne et édouardienne, l'Empire fut d'abord vécu comme une réalité positive, comme une échappatoire possible à une société métropolitaine figée voire comme un vecteur de propagation du tradeunionisme. Au cours de la seconde moitié du long XIXe siècle, les migrations intercontinentales ne s'effectuèrent en effet pas seulement de l'Europe vers les États-Unis, mais aussi des îles Britanniques vers les colonies et les dominions, ou encore d'un territoire de l'Empire britannique à un autre. Entre la fin des années 1880 et 1914, le Canada, l'Australie, la Nouvelle-Zélande et l'Afrique du sud virent ainsi leur population gonfler à vue d'œil, tant les ouvriers britanniques étaient nombreux (les Écossais, les Gallois et les Irlandais en particulier) à vouloir tenter leur chance au-delà des océans. Ni les moins débrouillards, ni les moins combatifs, ils emportèrent dans ces colonies de peuplement leur optimisme, leur savoir-faire mais aussi leurs traditions d'organisation. Le globe-trotter Tom Mann, dont les périples sont entrés dans la légende, fut donc tout sauf un cas isolé : son parcours de militant transnational est au contraire à rapprocher du vécu de milliers de syndicalistes dont les activités ne connurent pas de frontières.

\section{Des exportations fructueuses}

L'exportation du trade-unionisme au Canada fut si précoce qu'elle devança à la fois la fondation de la Confédération des provinces canadiennes (1867) et celle du TUC en Grande-Bretagne (1868). Avant même que le Canada unifié ne devienne officiellement un dominion anglais, la British Amalgamated Society of Engineers y avait pris pied (1853) et une branche canadienne de la British Amalgamated Society of Carpenters and Joiners vit le jour dès 1871. Certes, les unions de métiers britanniques ne furent pas le seul parent du syndicalisme canadien, le second géniteur étant bien sûr le syndicalisme états-unien, qui poussa ses ramifications jusqu'au nord des Grands Lacs dès les années 1860. Mais les questions de passeport sont peu pertinentes ici, les syndicats qui devaient se fédérer au sein de la Federation of Organized Trades and Labor Unions en 1881, puis au sein de l'AFL en 1886, étant eux-mêmes le plus souvent des enfants du trade-unionisme. Une déclinaison canadienne du TUC se constitua dès 1873, sous le nom de Canadian Labour Union. Et le gouvernement fédéral lui-même alla chercher son inspiration du côté britannique lorsqu'il décida de reconnaître le fait syndical : son Trades Union Act de 1872 fut copié presque mot pour mot sur le texte adopté par les Communes 
un an auparavant ${ }^{61}$. En Afrique du Sud, quoique plus tardive, la greffe tradeunioniste prit avec une rapidité comparable, là aussi autour de travailleurs qualifiés en provenance du Royaume-Uni ${ }^{62}$. Les syndicats les plus nombreux s'implantèrent chez les mineurs, dans le diamant d'abord (fin des années 1860) puis dans l'or (fin des années 1880). Aussi surprenant que cela puisse paraitre, les premiers bastions du trade-unionisme sud-africain se consolidèrent dans la région du Transvaal à une époque où celle-ci était redevenue un territoire boer. Ce fut au cours des années 1890 que s'y structurèrent, sur le modèle britannique, des organes chargés de la coordination interprofessionnelle: une Labour Union en 1892; le Johannesburg Trades Council l'année suivante ${ }^{63}$. Après la victoire britannique sur les Boers et le retour du Transvaal sous les couleurs de l'Union Jack en 1901, l'organisation des ouvriers anglophones continua à aller de l'avant, avec l'émergence d'un Transvaal Independent Labour Party et d'une Transvaal Federation of Trades. À plusieurs reprises, cette dernière démontra aux propriétaires des mines qu'elle représentait une force avec laquelle il fallait compter, organisant en 1902 et 1907 des grèves de grosse ampleur contre la déqualification du travail ${ }^{64}$. Au Canada comme en Afrique du Sud ${ }^{65}$, les ouvriers britanniques expatriés incarnèrent donc l'expansion transnationale du trade-unionisme et la foi dans ses possibilités de développement. Arrivant dans des contrées perçues comme vierges, parce que la présence blanche y était encore toute récente, ils pouvaient en effet convoiter l'espoir d'y construire un mouvement ouvrier plus puissant qu'en métropole, fort de l'expérience du TUC mais aussi de l'absence d'une hiérarchie sociale ancienne et ossifiée.

Cette espérance fut portée à son paroxysme par les ouvriers britanniques immigrés en Australasie et par leurs descendants. En Australie, on recensait dès 1850 une centaine de trade-unions. Les premières à se former furent des branches locales des plus anciennes unions de métiers, par exemple celle des mécaniciens ou encore celle des typographes ${ }^{66}$. Dès 1856 , elles imposèrent la journée de huit heures comme norme nationale pour les ouvriers qualifiés et, au cours des décennies suivantes, des organisations professionnelles plus larges se constituèrent dans ces secteurs économiques en croissance accélérée qu'étaient l'extraction minière et le transport. Couronnant ses efforts dispersés, la première confédération syndicale panaustralienne se cristallisa en 1879. On comprend donc qu'en 1890, les marins et les dockers d'Adélaïde, de Brisbane, de Melbourne, de Sydney et d'ailleurs aient pu se sentir assez forts pour suivre l'exemple des new unionists britanniques et s'engager dans un conflit social généralisé contre leurs employeurs. Malgré le soutien des mineurs, leurs deux mois de grève finirent en déroute. Mais le mouvement ouvrier rebondit bientôt de façon spectaculaire en optant pour la voie électorale et en se lançant, avec un succès grandissant, à l'assaut du pouvoir politique. À la suite du

${ }^{61}$ Jean SAGNES, Histoire du syndicalisme dans le monde ..., op. cit., pp. 64-66.

${ }^{62}$ H.J. et R.E. SIMONS, Class and Colour in South Africa 1850-1950, Harmondsworth : Penguin, 1969, $702 \mathrm{p}$.

${ }^{63}$ Un des principaux animateurs de cette instance, Robert Noonan, deviendrait célèbre en Grande-Bretagne après sa mort en 1911, sous le pseudonyme de Robert Tressell, pour son roman The Ragged-Trousered Philanthropists publié en 1914.

${ }^{64}$ Jean SAGNES, Histoire du syndicalisme dans le monde ..., op. cit., pp. 464-465.

${ }^{65}$ Les territoires britanniques d'Afrique du Sud furent proclamés « Union sud-africaine » en 1910.

${ }^{66}$ Leurs pionniers racontent qu'elles furent fondées en pleine mer, avant même l'arrivée desdits mécaniciens et typographes aux antipodes. 
Labor Party de Nouvelle-Galles du Sud, créé en 1891 (trois and après le Scottish Labour Party mais quinze ans avant le Labour Party britannique), des partis travaillistes émergèrent à quelques années d'intervalle dans chacun des États australiens. Parmi eux, le Labor Party du Queensland fut le premier, en 1899, à accéder au pouvoir gouvernemental - un événement de portée mondiale, puisque jamais encore un parti ouvrier ne s'était retrouvé aux commandes d'un appareil d'État. L'essai fut transformé dans le «Commonwealth d'Australie» (unifié en 1901), lorsque le Labor Party pan-australien conquit à son tour la majorité, relative en 1904 et en 1908, puis absolue en 1910. Dans les années 1890, l'Australie passait déjà aux yeux des prolétaires britanniques pour «le paradis du travailleur» (the Workingman's Paradise) et il n'est pas un grand nom du mouvement ouvrier qui n'ait sacrifié à l'incontournable voyage en Océanie ${ }^{67}$. Mais quand elle devint le premier pays au monde gouverné par des travaillistes, elle acquit une stature plus prestigieuse encore. Pour le syndicaliste britannique moyen, il était manifeste que l'élève avait dépassé le maître ${ }^{68}$. L'expérience néo-zélandaise suscita un engouement tout aussi compréhensible. Les lettres de «frères » émigrés que publia la presse ouvrière britannique ou qu'on retrouve dans les archives de tel ou tel section syndicale regorgent elles aussi de métaphores paradisiaques. Avant même que les trade-unionistes de Nouvelle-Zélande ne fondent leur Parti travailliste (1914), on évoquait déjà un havre «socialiste », où les femmes avaient le droit de vote (1893) et les vieux ouvriers le droit à une pension (1898). Dès 1894, un Conciliation and Arbitration Act avait mis un frein à l'arbitraire patronal en instituant une procédure tripartite obligatoire dans le règlement des conflits d'entreprise. Et en 1907, l'année même où le pays accéda au statut de dominion, le leader de la grande grève maritime de 1890, J.A. Millar, devenait ministre du travail. La migration australasienne du trade-unionisme avait fait bien plus qu'accoucher de copies conformes : à la veille de la Grande Guerre, elle offrait au monde un modèle à suivre.

Certes, les progrès accomplis par le syndicalisme à travers l'Empire ne suivirent pas un cours tranquille ni un rythme uniforme. Les patrons canadiens n'hésitaient pas à emprunter à leurs homologues des États-Unis des méthodes musclées pour réprimer l'activité syndicale. Quant aux tensions sociales en Afrique du sud, et même en Nouvelle-Zélande ${ }^{69}$, elles débouchèrent sur des débuts de guerre civile au cours de l'année 1913. L'Empire ne fut donc pas synonyme de mondialisation idéale pour les trade-unionistes ${ }^{70}$. Mais il contribua à élargir et leur

\footnotetext{
${ }^{67}$ Parmi les plus notables, on signalera les époux Webb, les époux MacDonald, Ben Tillett et bien sûr Tom Mann, dont l'enthousiasme pour le parlementarisme vira au rejet pur et simple au cours de son long séjour (1902-1908).

${ }^{68}$ Neville KIRK, 'The Australian "Workingman's Paradise" in Comparative Perspective, 1890-1914' in KIRK 2003, pp. 59-148.

${ }^{69}$ Entre octobre et décembre 1913, les travailleurs néo-zélandais (au nombre desquels 5000 dockers, 2000 marins et 4000 mineurs) furent les acteurs d'une grève générale qui s'acheva par une sévère répression. Melanie NOLAN, Revolution. The 1913 Great Strike in New Zealand, Christchurch : Canterbury University Press, 2006, 320 p.

${ }^{70} \mathrm{Je}$ n'ai pas mentionné la naissance du syndicalisme dans l'empire britannique des Indes, car le scénario y fut très différent de celui suivi dans les colonies de peuplement. Comme la main d'œuvre d'origine britannique n'y représentait qu'une minorité infime de la population, les
} 
horizon mental, et leur champ d'activité, favorisant au Royaume-Uni la naissance d'une certaine conscience de classe internationale ${ }^{71}$. Au début du XXe siècle, recevoir des nouvelles de l'autre bout du monde, par un parent, un ami ou un camarade syndiqué installé en Colombie britannique ou à Auckland, était devenu monnaie courante, si bien que les conditions de vie et de travail sur les autres continents n'étaient plus des inconnues. L'un des conflits du travail les plus discutés au TUC de 1901 ne fut-il pas une grève de dockers britanniques vivant et travaillant à Gibraltar ${ }^{72}$ ?

\section{Une conscience de classe internationale à la fois impériale et raciale}

Mais cette nouvelle «conscience mondiale » n'était pas sans œillères et il serait sans doute plus juste de la qualifier de «conscience impériale», tant cet internationalisme avait partie liée avec la construction impériale. Aussi contradictoire que cela puisse paraître, les syndicalistes d'Albion, de même que leurs « camarades et cousins » d'outre-mer, furent des internationalistes hautement conscients de leur identité nationale, pour qui la fierté ouvrière était inséparable du patriotisme, voire du nationalisme britannique. Au cours de cette période 1868-1914 qui vit à la fois la classe ouvrière conquérir des droits nouveaux et la GrandeBretagne faire main basse sur de vastes portions du monde, il était somme toute assez naturel de s'identifier plus facilement à cet empire « sur lequel le soleil ne se couchait jamais ", dont on avait une connaissance de première main, qu'à la cause, plus abstraite, du prolétariat international. L'aventure coloniale, faut-il le rappeler, permit à plus d'un syndicaliste fiché sur liste noire par les patrons de sa ville de retrouver un emploi à l'autre bout du monde, voire d'y monter sa propre entreprise. Dans les milieux syndicaux, l'adhésion à l'impérialisme ne faisait guère débat et, même parmi les militants les plus à gauche, ceux qui votaient pour les candidats travaillistes ou prêtaient l'oreille à la propagande des socialistes, il n'y avait aucune raison particulière de contester le bien-fondé des conquêtes coloniales. Les rédacteurs de Justice (l'hebdomadaire de la SDF), du Clarion ou du Labour Leader dénonçaient à l'occasion les méthodes employées, mais le plus souvent pour se faire les avocats d'un «meilleur impérialisme ${ }^{73}$. Par ailleurs, lorsqu'il devint clair que l'Allemagne était en train de se doter d'une flotte militaire capable de rivaliser avec la Royal Navy, aussi bien Henry Hyndman que Robert Blatchford se firent les chantres de l'augmentation du budget militaire au nom de la défense nationale. Dans l'univers mental des trade-unionistes les moins politisés, une approche antiimpérialiste de l'ordre mondial n'avait donc aucune raison d'être. La seule occasion où la propagande anti-jingo de l'ILP fut largement comprise et reprise dans la classe ouvrière fut à la fin de la guerre des Boers, lorsque son coût humain et financier

rares syndicats constitués avant 1914 ne le furent pas par des trade-unionistes expatriés, mais par des travailleurs indigènes, sous drapeau nationaliste ou religieux.

${ }^{71}$ Sans la conscience d'une communauté d'intérêts entre salariés à l'échelle de l'Empire, il n'aurait pu y avoir après-guerre de grève trans-impériale telle que celle étudiée par Baruch HIRSON et Lorraine VIVIAN dans Strike Across the Empire: The Seamen's Strike of 1925 in Britain, South Africa and Australasia, Londres : Clio, 1992, 117 p.

${ }^{72}$ TUC, Annual Report 1901, pp. 45-47.

${ }^{73}$ Neville KIRK, 'The Rule of Class and the Power of Race: socialist attitudes to class, race and empire during the era of "new imperialism", 1899-1901' in KIRK 2003, pp. 149-218. 
éclata au grand jour. Mais dans les rangs syndicaux, on considérait en général comme allant de soi et le colonialisme, et la valeur du libre-échange comme garant de relations internationales équilibrées. Le fait que la libre concurrence entre les économies nationales ait engendré des rivalités porteuses de risques de guerre mondiale fut certes souligné à chaque congrès ouvrier international à partir de 1907. Les trade-unions appelèrent certes à plusieurs reprises à des journées d'action internationale contre l'affrontement qui s'annonçait. Mais cela ne remit en cause ni leur attachement à la couronne, ni celui à l'empire, un attachement distrait mais profond, distrait parce que profond ${ }^{74}$.

Plusieurs événements sont révélateurs de la mentalité tranquillement chauvine, et à l'occasion impérialiste voire raciste, des syndicalistes britanniques dans la décennie qui précéda la Première Guerre mondiale. On peut citer d'abord leur campagne de 1904 contre « l'esclavage chinois » au Transvaal. Les propriétaires des mines avaient fait venir des travailleurs asiatiques pour pouvoir leur verser des salaires moindres qu'aux mineurs d'origine britannique, ce que le TUC avait dénoncé avec vigueur. Mais en prenant position pour leur expulsion immédiate, sans envisager leur embauche à des conditions plus humaines, il cautionnait cette idée que la présence de travailleurs jaunes en Afrique du Sud constituait en soi une menace pour l'ouvrier anglophone blanc et que le maintien des salaires à un niveau acceptable passait par leur exclusion. C'était aussi partir du principe que les ouvriers asiatiques étaient incapables de s'organiser et, par nature, réfractaires au syndicalisme. Il y avait là les germes du racisme qui s'exprimerait avec moins de retenue encore en 1914, lors de la bataille contre le «Péril Jaune » évoquée plus haut $^{75}$. Dans un autre registre, on se doit de mentionner les réticences du TUC à soutenir les luttes menées par les salariés irlandais, à Belfast en 1907 mais surtout à Dublin en 1913. Au niveau des Trades Councils des principales villes de GrandeBretagne, le soutien matériel et moral fut réel. Mais au niveau de l'état-major, on raisonna comme à propos d'une affaire étrangère, en trade-unioniste anglais plus que britannique. Les motifs de prudence furent multiples. Appuyer James Connolly, Jim Larkin et leur Irish Transport and General Workers' Union en appelant les ouvriers anglais à la grève générale aurait équivalu à renier Sexton (qui avait exclu Larkin de sa National Union of Dock Labourers en 1908). Cela aurait signifié tourner le dos à la modération traditionnelle du trade-unionisme, pour l'engager dans la voie révolutionnaire défendue alors par Daniel De Leon ou les Industrial Workers of the World (IWW) - une option inimaginable, bien sûr. Et puis une grève de dockers irlandais, c'était presque une grève de barbares, en comparaison avec une grève de chaudronniers anglais, économes, abstinents, respectables et bons protestants. L'expérience de 1913 révéla donc à quel point la solidarité prolétarienne dont se réclamaient tant Henderson que Tillett pouvait être à géométrie variable. Elle fut, en l'occurrence, rigoureusement insulaire. On évoquera enfin la campagne de solidarité que le TUC initia en février 1914 afin de venir en aide à neuf militants qui venaient

\footnotetext{
${ }^{74}$ Un exemple de ce loyalisme : le 13 juillet 1902, dans toutes les grandes villes du pays, les syndicalistes se joignirent avec drapeaux et orchestres aux défilés en l'honneur du couronnement d'Edouard VII, aux côtés des fanfares patronales, policières et militaires.

${ }^{75}$ Jonathan HYSLOP, "The Imperial working class makes itself "white": White Labourism in Britain, Australia and South Africa before the First World War', Journal of Historical Sociology, vol. 12, n 4, décembre 2002, pp. 398-421.
} 
d'être expulsés de l'Union sud-africaine pour atteinte à l'ordre public. Ce combat pour les droits des Trade Unionists prit en effet d'abord la forme d'un combat pour les droits des British Subjects. Bien sûr, les plus fameux orateurs du mouvement ouvrier expliquèrent, meeting après meeting, que c'était une question de solidarité de classe. Mais leurs envolées prirent pour cibles uniques les généraux boers qui avaient conduit la répression, pas le gouverneur de l'Union sud-africaine (nommé directement par Londres) qui l'avait couverte ni les braves Tommies qui l'avaient exécutée. De plus, on justifia l'action des neuf déportés par leur refus de tomber aussi bas que les travailleurs noirs, ce qui revenait à considérer d'une part que les ouvriers indigènes étaient par définition imperméables au syndicalisme, d'autre part que leur position subalterne était dans l'ordre des choses ${ }^{76}$.

Le trade-unionisme, en se mondialisant, avait reproduit une caractéristique qui avait été la sienne depuis 1868 jusqu'à 1889 au moins : la méfiance envers les non qualifiés, forcément synonyme, dans les colonies de peuplement, d'ostracisme envers les prolétaires de couleur, qu'ils soient indigènes ou « importés ». Si bien des militants du Cap ou de Wellington étaient des enfants du «nouveau syndicalisme», initiés à l'action revendicative à Glasgow ou à Liverpool au cours de la grande tempête des années 1889-1890, ils en retinrent un certain radicalisme dans les moyens d'action plus que la volonté d'organiser la totalité des salariés. Car ils n'étaient plus, dans les colonies, ni les plus nombreux, ni les plus bas dans l'échelle sociale. En Afrique du Sud, l'utilisation par le patronat des paysans boers ou des Africains comme briseurs de grève convainquit l'immense majorité des syndicalistes que leur salut passait par l'exclusion des «autres», chemin qui devait les mener après-guerre sur la voie de l'Apartheid ${ }^{77}$. Quant aux rejetons australiens du tradeunionisme, non contents de laisser leur gouvernement parquer les Aborigènes en marge de leur "paradis ouvrier », ils exigèrent de lui qu'il en ferme promptement les portes aux nombreux immigrés d'Asie orientale: dans les années 1890, ils marchandèrent leur soutien au Parti conservateur contre la promesse d'une politique protectionniste sur les plans douanier et migratoire ${ }^{78}$. Syndicalisme aux dimensions internationales, le trade-unionisme de la Belle Epoque fut donc inséparablement, et internationaliste et impérialiste. Cela ne fut pas sans conséquence quand la mondialisation à l'œuvre aboutit au conflit ouvert entre puissances industrielles et militaires rivales.

\section{Août 1914, le choix de la nation}

En septembre 1914, pour la première fois depuis 1868, le TUC ne tient pas congrès. La guerre tant redoutée vient de commencer et le mouvement syndical, après quelques déclarations de pacifisme, choisit de faire profil bas. Le TUC n'est pas paralysé par la surprise : aux congrès de l'Internationale Socialiste (à Stuttgart en 1907, puis à Copenhague en 1910), des résolutions ont été votées appelant à une

\footnotetext{
${ }^{76}$ Logie BARROW, 'White solidarity (with South African strikers) in 1914', pp. 275-287 in Raphael SAMUEL (dir.), Patriotisms: The Making and Unmaking of National Identities, vol. 1, Londres : Routledge, 1989.

${ }^{77}$ En 1922 , la première grève générale des travailleurs sud-africains adopta le slogan suivant : 'Workers of the World, Unite and Fight for a White South African Commonwealth'.

${ }^{78}$ Jean SAGNES, Histoire du syndicalisme dans le monde ..., op. cit., p. 378.
} 
action résolue des ouvriers de tous les pays contre une guerre universelle qu'on savait imminente. Face à une mondialisation capitaliste porteuse de dangereuses tensions, même les dirigeants du TUC et du Parti travailliste ont déclaré à l'occasion qu'il fallait savoir opposer l'action internationale des travailleurs, seule capable de faire prévaloir l'entente entre les peuples. Mais en se prononçant dès le 24 août 1914 pour une «trêve sociale » et pour l'arrêt des grèves, le TUC fait le choix inverse : il tire un trait sur son internationalisme proclamé et sur l'option, préparée aussi peu sérieusement en Grande-Bretagne que dans les autres pays industrialisés, d'une résistance ouvrière à la guerre, pour embrasser la voie de l'accommodement avec le pouvoir politique et économique national ${ }^{79}$. Dès septembre 1914, au moment où le monde plonge dans la tourmente, l'activité des trade-unions n'a plus qu'un objectif : atténuer autant que possible les conséquences matérielles de la guerre sur les travailleurs, à travers des War Relief Committees, aux fonctions purement humanitaires et non pas revendicatives. Non seulement aucune tentative concrète n'est faite pour orchestrer une protestation syndicale internationale contre la guerre, mais le thème de l'internationalisme prolétarien lui-même disparait de la rhétorique trade-unioniste. Car en quelques semaines, le TUC de même que son émanation politique, le Parti travailliste, se rallient aux buts de guerre de l'État britannique et de nombreux dirigeants nationaux ou régionaux du mouvement ouvrier britannique accèdent alors à des postes officiels qui ne leur étaient auparavant attribués qu'au compte-goutte. Le 2 septembre, le TUC soutient la campagne de recrutement de l'armée ${ }^{80}$.

Que révèle la décision d'août 1914 ? Elle met en évidence le fait que les liens des directions syndicales avec les classes dirigeantes, tant sur le plan national qu'à l'échelle des localités, étaient autrement plus solides qu'avec le mouvement ouvrier international. Elle est révélatrice aussi d'un certain pragmatisme : s'opposer à la guerre aurait impliqué le risque de voir les syndicats interdits, c'est-à-dire de voir le bel édifice construit depuis 1868 réduit à néant. Snowden, Thorne et leurs semblables ne voulurent pas prendre ce risque. En s'engageant en faveur de l'unité nationale, ils invitèrent ceux qui leur faisaient confiance à entrer sous les drapeaux, ce qui fut dramatique à plus d'un titre. Le syndicalisme britannique perdit dans les tranchées des milliers de militants jeunes et combatifs, précisément ceux qui avaient fait leur apprentissage entre 1911 et 1914. Mais le puissant syndicalisme allemand fut lui aussi saigné à blanc par la guerre, certains de ces meilleurs éléments tombant justement sous les balles de cette génération du Great Labour Unrest. En 1915, le TUC prit certes l'initiative d'un nouveau congrès international, mais réservé aux syndicalistes des pays de l'Entente. En excluant par principe les syndicalistes des pays « ennemis », il confirmait son allégeance au gouvernement britannique et son parti pris national en ces temps de guerre mondiale. En termes purement organisationnels, le choix national s'avéra payant pour le TUC. Les grèves qui reprirent à partir de 1916 confortèrent son rôle d'intermédiaire incontournable pour le gouvernement et les employeurs. En échange de la promesse qu'il saurait contenir les mouvements revendicatifs, le TUC décrocha des avancées significatives en matière de sécurité de l'emploi et de reconnaissance syndicale, ce qui accrut

\footnotetext{
${ }^{79}$ Andrew L. MORTON et George TATE, The British Labour Movement 1770-1920, op.cit, pp. 255-259.

${ }^{80}$ Henry PELLING, A History of British Trade Unionism, op.cit., p. 150.
} 
notablement sa crédibilité auprès des travailleurs ${ }^{81}$. Pendant la guerre, les tradeunions virent leurs effectifs doubler. Avec le coup de pouce représenté par la pénurie de main d'œuvre, ils passèrent de 4 à 8 millions en quatre ans, alors qu'il avait fallu près de deux décennies au TUC pour passer de 1 à 2 millions d'adhérents ${ }^{82}$. La progression quasi exponentielle autorisée par le repli insulaire de 1914 conforta, on s'en doute, une méfiance à long terme pour « l'international ».

\section{Conclusion}

Dans sa jeunesse, le syndicalisme britannique eut donc à se poser un certain nombre de questions qui, depuis une quinzaine d'années, sont redevenues d'actualité, et pas seulement pour les militants du Royaume-Uni. Face à l'internationalisation des échanges commerciaux et financiers, le monde du travail n'a-t-il d'autre choix qu'entre libre-échange et protectionnisme ? Face à la mise en concurrence des ouvriers de toutes les nations, comment échapper au nivellement par le bas? Dans un contexte de compétition exacerbée entre grandes puissances rivales, quels liens de solidarité est-il possible de créer entre salariés de pays différents? Les réponses proposées à l'époque par les trade-unionistes furent multiples, variant selon leurs sympathies politiques, leur appartenance professionnelle ou leur niveau de responsabilité dans la hiérarchie syndicale, variant aussi au rythme des mutations du paysage économique. On peut néanmoins considérer qu'entre 1868 et 1914, la majorité des syndicalistes britanniques se dota, au fil des expériences, d'une vision commune de la mondialisation capitaliste en cours sous leurs yeux, cette globalisation qu'ils ne désignaient pas encore sous ce vocable mais dont la présence dans leur vie était de plus en plus manifeste. Cette Weltanschauung, moins explicite qu'implicite, faite de bric et de broc plutôt que savamment unifiée, vécue au quotidien plus que théorisée, articulait engagement a minima vis-à-vis du mouvement ouvrier international, confiance dans les vertus du libéralisme et fierté impériale - trois traits intimement imbriqués qui expliquent l'aisance avec laquelle les dirigeants du TUC mirent en sourdine la thématique internationaliste en août 1914 au profit d'un franc soutien à l'effort de guerre contre l'Allemagne, de même que la rareté de résistances spontanées à ce choix parmi les syndiqués de base.

Comment le TUC se positionne-t-il aujourd'hui vis-à-vis de la mondialisation? Dans les années 1970, le TUC défendait une ligne résolument protectionniste. La campagne contre l'entrée du Royaume-Uni dans le Marché Commun en 1972, par exemple, fut axée sur la menace de régression sociale qu'aurait représenté cet abaissement des frontières douanières. Puis, dans les années 1980, laminé par la crise et par une législation nationale de plus en plus paralysante, le TUC se tourna vers la CEE en quête de soutiens et se fit même, au cours des années 1990, le champion de la solidarité internationale. Depuis l'arrivée de John Monks à la tête de la Confédération Européenne des Syndicats (la CES, ou European Confederation of Trade Unions), le syndicalisme britannique a multiplié comme sans doute jamais auparavant les gages de son engagement transnational, de

\footnotetext{
${ }^{81}$ Ainsi, la NSFU de Havelock Wilson obtint en 1917 la création d'un National Maritime Board, qui l'associait à la gestion de l'embauche dans la marine marchande.

${ }^{82}$ G.D.H COLE, 1949, p. 597.
} 
la mise sur pied des premières manifestations européennes au lancement d'une journée mondiale pour le «travail décent ( Fair Work), en passant par l'envoi de délégations conséquentes aux rassemblements altermondialistes de Seattle en 1999 et de Gênes en 2003. Le mal aurait-il accouché d'un bien ? Le Royaume-Uni ayant rétrogradé, au cours du XXe siècle, de la première à la quatrième place, son État providence modèle ayant été, depuis trente ans, soumis à rude épreuve, on pourrait avoir l'impression que le trade-unionisme, tombé de son piédestal, a fini par tourner la page de l'isolationnisme et par rompre définitivement avec ses démons d'avant 1914.

Le tableau, pourtant, est à nuancer. Quand une usine ferme ses portes en Grande-Bretagne, le discours sur la nécessité du «produire britannique, acheter britannique » ou de surtaxer les produits en provenance des pays où la main-d'œuvre est moins bien payée refait souvent surface, comme en écho au 'Buy British' de Joseph Chamberlain. Quant à l'enthousiasme manifesté pour une construction européenne qui se fait sur la base de l'économie de marché et de la recherche de la compétitivité vis-à-vis des concurrents états-uniens et japonais, elle n'est pas sans rappeler la confiance innée que faisait le TUC édouardien à une construction impériale impitoyablement capitaliste qui se voulait, elle aussi, un modèle de civilisation pour le monde. L'internationalisme professé aujourd'hui est-il moins ambigu qu'au XIX ${ }^{\mathrm{e}}$ siècle ? Les syndicalistes britanniques ont montré récemment le souci qu'ils avaient d'organiser les travailleurs d'origine immigrée ou de prendre langue, au sein des entreprises multinationales, avec leurs collègues étrangers. Mais au Royaume-Uni comme ailleurs, la «mondialisation par en bas » semble toujours avoir un temps de retard sur la «mondialisation par en haut » et ceux qui prétendent défendre les intérêts des salariés peinent à formuler une vision de la globalisation qui ne soit pas calquée sur celle des employeurs et des hommes d'État ${ }^{83}$. La crise actuelle du capitalisme globalisé ne s'achèvera évidemment pas par un cataclysme identique à la Première Guerre mondiale qui sonna le glas de la première mondialisation. Pourtant ses conséquences sociales risquent d'être si rudes pour les classes populaires britanniques qu'il serait vital que les trade-unionistes disposent d'une grille de lecture qui leur soit propre. L'expérience de la seconde moitié du long $\mathrm{XIX}^{\mathrm{e}}$ siècle ne leur offre certes aucune clé pour traverser les épreuves qui s'annoncent ni pour revivifier un mouvement syndical affaibli. Au moins est-elle riche d'indications sur certains écueils à éviter.

\section{Bibliographie}

BALIBAR, Etienne et WALLERSTEIN, Immanuel, Race, nation, classe. Les identités ambiguës, Paris : La Découverte, 1988, 307 p.

BERGER Suzanne, Notre première mondialisation. Leçons d'un échec oublié, Paris : Editions du Seuil et La République des idées, 2003, 95 p.

83 Anne-Catherine WAGNER, Les classes sociales dans la mondialisation, Paris: La Découverte, 2007, pp. 67-82. 
BROEZE, Frank, "Militancy and pragmatism: an international perspective on maritime labour 1870-1914”, International Review of Social History, 1991, vol. 36, pp. 165-200.

DAVIES, Sam, Dock Workers: International Explorations in Comparative Labour History 1790-1970, Aldershot: Ashgate, 2000, 863 p.

HIRSON, Baruch et VIVIAN, Lorraine, Strike Across the Empire. The Seamen's Strike of 1925 in Britain, South Africa and Australasia, Londres, Clio, 1992, 117 p.

HOBSBAWM, Eric John, The Age of Empire 1875-1914, Londres : Weidenfeld and Nicolson, 1987, 404 p.

HYSLOP, Jonathan, “The Imperial working class makes itself 'white': White Labourism in Britain, Australia and South Africa before the First World War", Journal of Historical Sociology, vol. 12, n 4, décembre 2002, pp. 398-421.

KIRK, Neville, Comrades and Cousins. Globalization, Workers and labour Movements in Britain, the USA and Australia from the 1880s to 1914, Londres : Merlin Press, 2003, 230 p.

LUNN, Kenneth, Race and Labour in Twentieth Century Britain, Londres : Frank Cass, 1985, $186 \mathrm{p}$.

MASON, Paul, Live Working or Die Fighting: How the Working Class Went Global, Londres : Harvill Secker, 304 p. year?

NOLAN, Melanie, Revolution. The 1913 Great Strike in New Zealand, Christchurch : Canterbury University Press, 2006, 320 p.

PILCH, Tony (dir.), Trades Unions and Globalisation, Londres : Smith Institute, 2007, 86 p.

REID, Alistair J., United We Stand. A History of Britain's Trade Unions, Londres : Penguin, 2005, $330 \mathrm{p}$.

RODRIGUEZ GARCIA, Magaly, Labour Internationalism: Different Times, Different Faces, Revue Belge de Philologie et d'Histoire, vol. 84, n 4, 2006, 182 p.

SILVER, Beverley J., Forces of Labor. Workers' Movements and Globalization since 1870, Cambridge : Cambridge University Press, 2003, 238 p.

TABILI, Laura, 'We Ask for British Justice': Workers and Racial Difference in Late Imperial Britain, Ithaca : Cornell University Press, 1994, 255 p.

TILLY, Charles et HAIMSON, Leopold, Strikes, Wars and Revolutions in an International Perspective: Strike Waves in the Late Nineteenth and Early Twentieth Centuries, Cambridge : Cambridge University Press, 1989, 536 p.

TRENTMANN, Frank, Free Trade Nation. Commerce, Consumption and Civil Society in Modern Britain, Oxford : Oxford University Press, 2008, 450 p.

VAN DER LINDEN, Marcel, Transnational Labour History, Aldershot : Ashgate, 2003, 226 p.

VAN DER LINDEN, Marcel, "Global Labour History and the "Modern World System': thoughts at the twenty-fifth anniversary of the Fernand Braudel Centre", 
International Review of Social History, vol. 46, 2001, pp. 423-459.

VAN DER LINDEN, Marcel, "The national integration of European working classes (1871-1914). Exploring the causal configuration", International Review of Social History, vol. 33, 1988, pp. 285-311.

VAN DER WALT, "The first globalisation and transnational labour activism in Southern Africa: white labourism, the IWW and the ICU, 1904-1934", African Studies, vol. 66, n 2-3, août 2007, pp. 223-251.

WAGNER, Anne-Catherine, Les classes sociales dans la mondialisation, Paris : La Découverte, 2007, 117 p.

WALLERSTEIN Immanuel, Processes of the World System, Londres : Sage, 1980, $320 \mathrm{p}$.

WATERMAN Peter, Understanding Socialist and Proletarian Internationalism. The impossible past and possible future emancipation on a world scale, La Hague: Institute of Social History, 1991, 66 p.

WINDMULLER, J.P., The International Trade Union Movement, Londres : Kluwer, 1980. 